\title{
Correlation and prediction of biodiesel density for extended ranges of temperature and pressure
}

\author{
Nieves M.C.T. Prieto ${ }^{a}$, Abel G.M. Ferreira ${ }^{a, *}$, António T.G. Portugal ${ }^{a}$, Rui J. Moreira ${ }^{a}$, \\ Jaime B. Santos ${ }^{b}$ \\ ${ }^{a}$ Department of Chemical Engineering, University of Coimbra, Polo II, Rua Silvio Lima, 3030-970 Coimbra, Portugal \\ ${ }^{\mathrm{b}}$ Department of Electrical and Computers Engineering, University of Coimbra, Polo II, Rua Silvio Lima, 3030-970 Coimbra, Portugal
}

\section{H I G H L I G H T S}

- The density of cottonseed biodiesel as function of temperature and pressure.

- Density data for 19 biodiesels were correlated with GMA equation of state.

- Thermal expansivity, isothermal compressibility and internal pressure.

- New predictive density methods for large $(T, p)$ ranges are proposed.

\section{A R T I C L E I N F O}

\section{Article history:}

Received 2 May 2014

Received in revised form 29 July 2014

Accepted 30 September 2014

Available online 12 October 2014

\section{Keywords:}

Biodiesel

Density

GMA equation of state

Correlation

Prediction

\begin{abstract}
A B S T R A C T
The knowledge of biodiesel density over large ranges of temperature and pressure is important for predicting the behavior of fuel injection and combustion systems in diesel engines, and for the optimization of such systems. In this study, cottonseed oil was transesterified into biodiesel and its density was measured at temperatures between $288 \mathrm{~K}$ and $358 \mathrm{~K}$ and pressures between $0.1 \mathrm{MPa}$ and $30 \mathrm{MPa}$, with expanded uncertainty estimated as $\pm 1.6 \mathrm{~kg} \mathrm{~m}^{-3}$. Experimental pressure-volume-temperature $(p V T)$ cottonseed data was used along with literature data relative to other 18 biodiesels, in order to build a database used to test the correlation of density with temperarure and pressure using the GoharshadiMorsali-Abbaspour equation of state (GMA EoS). To our knowledge, this is the first that density measurements are presented for cottonseed biodiesel under such high pressures, and the GMA EoS used to model biodiesel density. The new tested EoS allowed correlations within $0.2 \mathrm{~kg} \mathrm{~m}^{-3}$ corresponding to average relative deviations within $0.02 \%$. From these results of correlation with the GMA EoS mechanical coefficients such as thermal expansivity, isothermal compressibility and internal pressure were calculated. In spite of their effect in power and fuel injection, those properties are rarely presented for biodiesel, especially at high pressures. As a remarkable result of this study, it was found a crossing point for the thermal expansivity, where isothermic curves cross. The built database was used to develop and test two new full predictive models valid up to $373 \mathrm{~K}$ and $130 \mathrm{MPa}$. One of the proposed predictive methods (4PGMA) followed from the GMA EoS, and the other (DU) was derived from the observed linear relation between density and degree of unsaturation (DU), which depended from biodiesel FAMEs profile. The average density deviation of 4PGMA was only about $2 \mathrm{~kg} \mathrm{~m}^{-3}$, and $3 \mathrm{~kg} \mathrm{~m}^{-3}$ for the DU method within the temperature and pressure limits of application. These results represent appreciable improvements in the context of density prediction at high pressure when compared with other equations of state.
\end{abstract}

(c) 2014 Elsevier Ltd. All rights reserved.

\section{Introduction}

Chemically, biodiesel is a mixture of monoalkyl esters of long chain fatty acids obtained from vegetable oils, animal fats, or their

\footnotetext{
* Corresponding author. Tel.: +351 239798 729; fax: +351 239798703.

E-mail address: abel@eq.uc.pt (A.G.M. Ferreira).
}

mixtures. It is produced by transesterification of triglycerides with a short chain alcohols, such as methanol or ethanol in the presence of a catalyst, leading to fatty acid methyl esters (FAMEs) or fatty acid ethyl esters (FAEEs) and glycerol. The main components of biodiesel are palmitate, stearate, oleate, and linoleate esters [1,2]. In diesel engines, the injection is one of the most important parameters for high performance. An appropriate quantity of fuel must be 
delivered into the engine cylinder and mixed with air to achieve proper combustion mixture. This operation is carried out under pressure, usually at $p \approx(15-50) \mathrm{MPa}$ and moderate temperature $T \approx(300-350) \mathrm{K}$, and is strongly affected by the fuel density [3$5]$. With the common rail injection technology the pressure can reach up 100-120 MPa [6,7]. Therefore the simulation of biodiesel production, blending, and design of injection systems requires accurate knowledge of volumetric properties over wide ranges of pressure and temperature. Literature usually reports biodiesel density measurements made close to the ambient temperature (285295) $\mathrm{K}$ and atmospheric pressure [8-14] and few measurements of this property have been reported in wider temperature ranges [15-20]. The inclusion of pressure has been made in the works by Pratas et al. [1], Tat and Van Gerpen [2,21,22], Nikolic et al. [23], Aparício et al. [24], Dzida and Prusakiewicz [25], and recently by Chhetri and Watts [26] and Schedemann et al. [27]. Since density depends on the used raw material from which biodiesel was produced, FAMEs profile is crucial for applying the correlation and prediction models to that property, which also has not been provided by authors [23-25].

To correlate pure FAME and biodiesel densities the Tait equation of state (EoS) [28] has been used [1,24,27]. Pratas et al. [1] used this EoS to correlate density of pure FAME (methyl laurate, myristate, and oleate), methyl biodiesels from palm (P), soybean $(\mathrm{S})$, and rapeseed $(\mathrm{R})$ oils, binary (RP, SP, SR) mixtures, and ternary mixture (SRP) for temperatures from $283 \mathrm{~K}$ to $333 \mathrm{~K}$ and pressures up to $45 \mathrm{MPa}$. Schedemann et al. [27] used Tait equation to correlate data for methyl linoleate at temperatures between $278 \mathrm{~K}$ to $367 \mathrm{~K}$ and pressures between $0.4 \mathrm{MPa}$ and $130 \mathrm{MPa}$. The relative deviations in density obtained from those correlations have been usually lower than $0.01 \%$. Cubic equations of state such as the cubic-plus-association equation of state (CPA EoS) [29,30], and the volume translated Peng-Robinson (PR) equation of state (VTPR EoS) [31] have been applied to density correlation and prediction. The CPA EoS combines a physical contribution from a cubic density EoS (Soave-Redlich Kwong EoS) with an association term accounting for intermolecular hydrogen bonding and solvation effects, which disappears for non-associating components, such as esters. The VTPR EoS uses the cubic Peng-Robinson EoS in which the predictive UNIFAC group contribution method developed by Dortmund [32] is employed for calculation of the needed parameters. Pratas et al. [1] applied the CPA EoS to correlate pure FAME density, and the calculated pure component parameters were applied to predict the density of methyl biodiesels with deviations ranging from $0.79 \%$ to $2.5 \%$. Schedemann et al. [27] used the VTPR method to predict density data of methyl linoleate and biodiesel. For the biodiesel deviations $\approx 1 \%$ were found at $396.8 \mathrm{~K}$ and pressures up to $55 \mathrm{MPa}$ whereas at temperatures lower than $386.9 \mathrm{~K}$ and pressures up to $130 \mathrm{MPa}$ deviations ranged from $-1 \%$ to $-7 \%$. More complex EoS such as variants of SAFT EoS were also used. The SAFT EoS is based on a clear physical molecular model, assuming that a molecule is composed of chains of freely jointed spherical segments and several intermolecular forces are taken in consideration [33]. Recently Oliveira et al. [34] applied the soft-SAFT EoS to density prediction of FAMEs and of biodiesels measured by Pratas et al. [1] and obtained mean deviations of $0.49 \%$. Dong et al. [35] were the first to apply the PC-SAFT equation of state using group contribution methods for the calculation of parameters and prediction of FAMEs and biodiesel densities. For FAMEs at atmospheric pressure, deviations in density were less than $0.5 \%$, and for biodiesels studied by Pratas et al. [1] predicted densities were all within $1 \%$ deviation. Pratas et al. [36] extended a group contribution method developed for the prediction of molar volume (GCVOL) under high pressure. The prediction of biodiesel density with this method was made with relative deviations between $0.2 \%$ and $0.7 \%$. Recently Meng et al. [37] revised the modified Rackett equation proposed by Spencer and Danner [38] to predict biodiesel densities over wide temperature range (298-523) $\mathrm{K}$ at atmospheric pressure. The revised Rackett equation allowed the density prediction for three biodiesels with a maximum deviation of $0.42 \%$. An attempt was made to use fundamental relations of thermodynamics in particular the Helmholtz free energy [16] to model thermodynamic properties of biodiesel. Using this approach, biodiesel density was predicted within $0.6 \%$ deviation for temperatures between $278 \mathrm{~K}$ and $333 \mathrm{~K}$. A new interesting approach and never applied to biodiesel for the correlation of density is provided by the Goharshadi-Morsali-Abbaspour equation of state (GMA EoS), which was found valid for polar, non-polar, and H-bonded fluids [39]. The GMA EoS equation is based on the theory of the average potential energy and has shown linear behavior for various thermodynamic properties. The existence of such regularities is very important because they can be used for safe extrapolation in the density calculation for high pressures.

In this work, densities of cottonseed biodiesel produced by transesterification of oil (PCS) were measured at pressures between 0.1 and $30.0 \mathrm{MPa}$ and temperatures from $288 \mathrm{~K}$ to $358 \mathrm{~K}$ using a vibrating tube densimeter, model DMA 512P from Anton Paar. This work is part of a broader project aiming the determination of temperature and pressure dependences of the biodiesel thermophysical properties, and their use in the monitoring and control of this biofuel production. Density data regarding cottonseed biodiesel is very scarce in the literature compared with other FAME diesels. Nogueira et al. [40] presented density data at temperatures between 293.15 and $373.15 \mathrm{~K}$ at atmospheric pressure, and Alptekin and Canakci [10] presented the value at $288.15 \mathrm{~K}$. To the best of our knowledge, no high-pressure results were presented so far for this biodiesel. Cottonseed is a byproduct from cotton with high production level in many countries and it is envisaged as an alternative oleaginous species traditionally cultivated for biodiesel production [41,42]. Moreover, cottonseed biodiesel can be considered a second generation biofuel, since it has not been used in the human food chain and results from a cotton crop waste. Also the studies on production [43] and use of cottonseed biodiesel as fuel for engines are increasing [41,44].

Aiming to gather a sufficiently large amount of data, and for the sake of statistical significance for biodiesel density correlation and prediction, the measured densities for cottonseed made in this study were combined with biodiesel data provided by Pratas et al. [1], Tat and Van Gerpen [1,22], and Schedemann et al. [27].

The information regarding all biodiesels was included in the so constituted $p V T$ database and used to establish correlations using the GMA EoS, and the mechanical coefficients, such as the thermal expansivity, isothermal compressibility and internal pressure were calculated from this EoS. Two new models were developed to predict density as function of temperature and pressure. One of them was derived from the GMA EoS. The predictive GCVOL for high pressure used by Pratas et al. [36] was also applied to the fuels that constituted the built database. The relative deviations of the predicted densities against experimental data were calculated for accurate evaluation of the different predictive methods.

\section{Experimental}

\subsection{Materials}

The detailed specifications of all materials are summarized in Table 1, where the FAMEs and $\mathrm{N}$-heptane (used as eluent in gas chromatography) are presented. The terminology ( $\mathrm{Cm}: \mathrm{n})$ was used for FAMEs, where $m$ is the number of carbon atoms and $n$ the number of double bonds of the related fatty acid. Table 1 also reports 
Table 1

Sample material purities.

\begin{tabular}{|c|c|c|c|c|}
\hline Material & Supplier & $\begin{array}{l}\text { Cas } \\
\text { No. }\end{array}$ & $\begin{array}{l}\text { Sample purity } \\
\text { (wt.\%) }\end{array}$ & Properties \\
\hline Sodium methoxide & Fluka & $\begin{array}{l}124- \\
41-4\end{array}$ & $\geqslant 97$ & \\
\hline Methanol & $\begin{array}{l}\text { Carlo } \\
\text { Herba }\end{array}$ & $\begin{array}{l}67- \\
56-1\end{array}$ & $\geqslant 99.9$ & \\
\hline $\begin{array}{l}\text { Methyl mirystate } \\
\text { (C14:0) }\end{array}$ & Fluka & $\begin{array}{l}124- \\
10-7\end{array}$ & $\geqslant 99$ & \\
\hline $\begin{array}{l}\text { Methyl Pentadecanoate } \\
\quad(\text { C15:0) }\end{array}$ & Fluka & $\begin{array}{l}7132- \\
64-1\end{array}$ & $\approx 99$ & \\
\hline $\begin{array}{l}\text { Methyl palmitate } \\
\quad(\mathrm{C} 16: 0)\end{array}$ & Fluka & $\begin{array}{l}112- \\
39.0\end{array}$ & $\geqslant 99$ & \\
\hline $\begin{array}{l}\text { Methyl stearate } \\
\text { (C18:0) }\end{array}$ & Sigma & $\begin{array}{l}112- \\
61-8\end{array}$ & $\approx 99$ & \\
\hline Methyl oleate (C18:1) & Aldrich & $\begin{array}{l}112- \\
62-9\end{array}$ & $\approx 99$ & \\
\hline $\begin{array}{l}\text { Methyl linoleate } \\
\quad(\mathrm{C} 18: 2)\end{array}$ & $\begin{array}{l}\text { Acros } \\
\text { Organics }\end{array}$ & $\begin{array}{l}112- \\
63-0\end{array}$ & $\approx 99$ & \\
\hline $\begin{array}{l}\text { Methyl linolenate } \\
\quad(\mathrm{C} 18: 3)\end{array}$ & Fluka & $\begin{array}{l}301- \\
00-8\end{array}$ & $\geqslant 99$ & \\
\hline $\begin{array}{l}\text { Methyl } \\
\text { heptadecanoate } \\
(\mathrm{C} 17: 0)\end{array}$ & Fluka & $\begin{array}{l}1731- \\
92-6\end{array}$ & $\geqslant 99$ & \\
\hline $\mathrm{N}$-Heptane & $\begin{array}{l}\text { Sigma } \\
\text { Aldrich }\end{array}$ & $\begin{array}{l}142- \\
82-9\end{array}$ & 99 & \\
\hline Cottonseed oil & $\begin{array}{l}\text { Acros } \\
\text { Organics }\end{array}$ & 17711 & $\begin{array}{l}\text { Fatty acid } \\
\text { composition: } \\
\text { MeC14:0 and lower: } \\
\text { ca 1.5\%; MeC16:0 ca } \\
25 \% \text {; MeC18:0 ca } 3 \% \text {; } \\
\text { MeC18:1, } 16 \text { to } 24 \% \text {; } \\
\text { MeC18:2, 50-55\%; } \\
\text { MeC18:3 and higher } \\
<1.5 \%\end{array}$ & $\begin{array}{l}A V \leqslant 0.5 \mathrm{mg} \\
\mathrm{KOH} \mathrm{g} \mathrm{g}^{-1} \\
S V=185- \\
198 \mathrm{mg} \\
\mathrm{KOH} \mathrm{g}^{-1} \\
I V=95- \\
115 \mathrm{~g} \mathrm{I} / \\
100 \mathrm{~g} \\
U M<1.5 \% \\
n=1.4720- \\
1.4730 \\
\left(20^{\circ} \mathrm{C},\right. \\
589 \mathrm{~nm})\end{array}$ \\
\hline
\end{tabular}

$A V=$ acid value; $S V=$ Saponification value; $I V=$ Iodine value; $U M=$ unsaponifiable matter; $n=$ refractive index.

the name, purity, supplier, and CAS number of each compound used in this study.

\subsection{Cottonseed biodiesel preparation}

The transesterification of cottonseed oil was carried out in a $50 \mathrm{ml}$ three-necked double wall jacketed reactor. The reactor was equipped with a reflux condenser to avoid methanol losses, a magnetic stirrer, a digital thermometer (ERTCO-EUTECHNICS Model 4400 Digital thermometer) and one stopper to feed reagents. The reaction vessel was initially charged with a known amount of cottonseed oil (Acros Organics). Solutions of known amounts of sodium methoxide in methanol were prepared and fed to the reactor for transterification of the previously heated cottonseed oil. After feeding, the reactor was air tight closed, and the temperature maintained constant by circulating hot water through the vessel jacket. The reaction mixture was held at a temperature just above the boiling point of the alcohol i.e. around $65^{\circ} \mathrm{C}$. Excess alcohol was used to provide enough driving force for total conversion of the oil into methyl esters. After two hours of reaction the methyl ester formation process was completed, so the heating and stirring were stopped and the products were cooled and transferred to a sedimentation funnel. The ester layer containing mainly FAMEs, and the glycerol layer containing mainly glycerol and methanol were separated. The biodiesel was washed and dried under vacuum to remove impurities and traces of moisture, respectively.

\subsection{Biodiesel characterization}

The so produced FAMEs were analyzed by gas chromatography (GC) in a TRE METRICS 9001 gas chromatograph equipped with a flame ionization detector (FID). A fused silica capillary column DB-225 (J \& W Scientific, Agilent) of $30 \mathrm{~m}$ length, $0.15 \mu \mathrm{m}$ film, and $0.25 \mathrm{~mm}$ internal diameter were used. Samples $(1 \mu \mathrm{L})$ were injected at temperature of $280^{\circ} \mathrm{C}$ without split. Helium was used as the carrier gas at a flow rate of $1 \mathrm{ml} \mathrm{min}^{-1}$, and also used as auxiliary gas for the FID. The following temperature ramp was used: initial temperature of $70{ }^{\circ} \mathrm{C}$ maintained for $1 \mathrm{~min}$, followed by an increase of $10^{\circ} \mathrm{C} \mathrm{min}^{-1}$ up to $180{ }^{\circ} \mathrm{C}$, and then $3^{\circ} \mathrm{C} \mathrm{min}^{-1}$ up to $220^{\circ} \mathrm{C}$ maintained for $15 \mathrm{~min}$. The biodiesel components were quantified using heptadecanoate methyl ester as internal standard. Calibration curves were developed using different concentrations of each methyl ester in n-heptane with addition of internal standard. The composition ( $\mathrm{w} / \mathrm{w}) \%$ of the cottonseed biodiesel (PCS) was found from three injections: methyl myristate $(0.93 \pm 0.28) \%$, methyl palmitate $(26.76 \pm 1.56) \%$, methyl stearate $(2.81 \pm 0.29) \%$, methyl oleate $(17.89 \pm 1.71) \%$, and methyl linoleate (51.61 \pm 2.99$) \%$.

\subsection{Experimental density measurement}

Cottonseed biodiesel densities were determined using an Anton Paar DMA 60 digital vibrating tube densimeter, with a DMA 512P measuring cell. The temperature in the vibrating tube cell was measured with a platinum resistance probe (PT100). A Julabo F12-ED thermostatic bath with ethylene glycol was used as circulating fluid in the thermostat circuit of the measuring cell and the temperature was held constant to $\pm 0.01 \mathrm{~K}$. The required pressure was generated and controlled using a Pressure Generator model 50-6-15, High Pressure Equipment Co., with acetone as hydraulic fluid. The diameter of the metallic tube was $1.59 \times 10^{-3} \mathrm{~m}$, and the buffer had more than $1 \mathrm{~m}$ length, which guaranteed the inexistence of hydraulic liquid diffusion in the liquid contained within the densimeter cell. Pressures were measured with a pressure transducer (Wika Transmitter S-10, WIKA Alexander Wiegand GmbH \& Co.). A PCI-6220 data acquisition board (DAQ) from National Instruments (NI) was used for real time collection of period, temperature, and pressure values. For this task a Labview application was developed. Modules of temperature (NI SCCFT01) and pressure (NI SCC-CI20) were installed into a NI SC2345 bus and connected to the DAQ board. The measuring setup and the calibration of the vibrating tube densimeter were described with detail in a previous paper [45]. The performance of the densimeter was checked against water (Milli-Q) at temperatures $(298.15,318.15,328.15,338.15,358.15) \mathrm{K}$ and for each temperature different pressures $(0.1,10,20,30) \mathrm{MPa}$ were considered. At each $(T, p)$ coordinate the density was measured five times in increasing pressure direction, and other five times in decreasing pressure one. The repeatability in density was better than $0.1 \mathrm{~kg} \mathrm{~m}^{-3}$. The measured densities compared with the reference NIST data [46], showed relative deviations in the range $(0.03-$ $0.07) \%$, except for $358.15 \mathrm{~K}$ were deviations reached $0.15 \%$. The influence of viscosity on density uncertainty (damping effects on the vibrating tube) for liquids with viscosities less than $100 \mathrm{mPa} s$ can be important. An approximate value of such uncertainty was obtained using the method proposed by Anton Parr [47] for the DMA 512P densimeter. From densities and viscosities presented by Nogueira et al. [40] for babassu, soybean and cottonseed biodiesels the obtained uncertainty was $0.03 \mathrm{~kg} \mathrm{~m}^{-3}$ thus contributing with a negligible value to the combined standard uncertainty. The expanded uncertainties, $U$, were calculated with confidence level $95 \%$ (with coverage factor $k=2$ ) for temperature, pressure, and density. The expanded uncertainties in temperature and 
pressure were $U(T)= \pm 0.02 \mathrm{~K}$ and $U(p)= \pm 0.02 \mathrm{MPa}$, respectively. The combined standard uncertainty of the density measurements, estimated taking into account the influence of uncertainties associated with calibration equation [45], temperature, pressure, period of oscillations (six-digit frequency counter), viscosity, and density data of calibrating fluids was estimated as $\pm 0.81 \mathrm{~kg} \mathrm{~m}^{-3}$. Hence, the expanded uncertainty in the measurement of density by this method was estimated to be $U(\rho)= \pm 1.6 \mathrm{~kg} \mathrm{~m}^{-3}$.

\section{Density database for biodiesels}

The information concerning biodiesel density under high pressures with detailed FAMEs profile is available in literature as explained in Section 1. The composition of biodiesel is a crucial issue for suitable application of the thermodynamic property models. Pratas et al. [36] have shown that discrepancies in density data reported by different authors are usually due to differences in the oil composition, and not caused by experimental errors during measurements. Thus, biodiesel detailed composition must be known for reliable prediction of their densities. The database used for the development of density models containing 19 biodiesels was built using measurements made by Pratas et al. [1], Tat and Van Gerpen [2,21], and Schedemann et al. [27], and our measurements regarding cottonseed biodiesel is presented in Table 2 . The equations of state used for density correlation by those authors are also mentioned in that table. Tat et al. [22] presented density values at $294 \mathrm{~K}$ and up to $35 \mathrm{MPa}$ for methyl soy biodiesel. However, access to the values is difficult and uncertain because they are presented in graphic form. Their biodiesel had practically the same composition of $\mathrm{N} 21$ biodiesel, which was also measured up to $35 \mathrm{MPa}$ for temperatures between $293 \mathrm{~K}$ and $373 \mathrm{~K}$. Dzida and Prusakiewicz [25] measured density from $263 \mathrm{~K}$ up to $373 \mathrm{~K}$ at atmospheric pressure and the values at pressures up to $100 \mathrm{MPa}$ in the range (293-318) K were calculated following a numerical procedure proposed by Sun et al. [48]. However, the FAMEs profile was not presented, neither by Nikolić et al. [23] who made density measurements for rapeseed biodiesel at $293 \mathrm{~K}$ and up to $160 \mathrm{MPa}$ and presented density data in graphic form, which for our purpose was useless. Density as a function of temperature at atmospheric pressure for all fuels in the database is plotted in Fig. S1 (vd. supplementary material). Density decreases as temperature increases, as expected. Lower and upper density limits for the envelope density in the database correspond to N23 (methyl tallow) and N7 (methyl linolenate) fuels studied by Tat and Van Gerpen [2,21], respectively. This was expected since density increases with increasing content in unsaturated FAMEs and unsaturation level. According to the biodiesel composition, the degree of unsaturation $(D U)$ can be calculated taking into account the amount of monounsaturated and polyunsaturated FAMEs (wt.\%) present in the biodiesel by the empirical expression [49-51],

$D U=($ monounsaturated $C n: 1 ;$ wt. $\%)+2$ (polyunsaturated $C n: 2,3 ;$ wt.\%)

From Table 2, the degree of unsaturation of N23 and N7 biodiesels were 49 and 153, respectively, being the lowest and the highest values of $D U$ in database. The set encompassing the biodiesels presented by Pratas et al. [1], the cottonseed biodiesel and the fuel measured by Schedemann et al. [27] showed intermediate behavior in density as function of temperature compared with N7 and $\mathrm{N} 23$ biodiesels. All the fuels in the set presented lower contents in $\mathrm{C} 18: 3$ than $\mathrm{N} 7$ biodiesel. The $\mathrm{C} 18: 3$ content ranges from a minimum of $0.09 \%$ (P fuel, $D U=62.0$ ) to a maximum of $8.0 \%$ (SCHB fuel, $D U=117.4$ ). The cottonseed biodiesel showed a density value well in the middle of the (temperature, density) plot, corresponding to an intermediate $D U$. The degree of unsaturation is strongly dependent on the $\mathrm{C} 18: 2$ and C18:3 contents, which has great influence in the density, and therefore it is expected that this parameter might be important in density calculations. For this reason we have used this parameter to develop a predictive model of density.

\section{Results and discussion}

\subsection{Density of cottonseed biodiesel}

Conttonseed biodiesel $p V T$ data measured during our experiments is reported in Table 3 for temperatures between $288.15 \mathrm{~K}$ and $358.15 \mathrm{~K}$ and pressures between $0.1 \mathrm{MPa}$ and $30.0 \mathrm{MPa}$. To our knowledge these are the first measurements for cottonseed biodiesel under pressure. The experimental data showed that biodiesel density behaved as expected, meaning that density decreases as temperature increases and pressure drops. The density at $288.15 \mathrm{~K}$ and atmospheric pressure is $884.1 \mathrm{~kg} \mathrm{~m}^{-3}$ and, thus it is well within the limits between 860 and $900 \mathrm{~kg} \mathrm{~m}^{-3}$ required by the EN 14214 standard [52]. Comparing the density of cottonseed biodiesel with those from other fuel in our database, it was interesting to note that N21 had comparable values in the same temperature and pressure ranges. This was very likely due to the similar content in $\mathrm{C} 18: 2$, which is known to have an important contribution in density. Our density measurements were comparable with those presented by Nogueira et al. [40], whose measurements were made at $(293.15,313.15,333.15,353.15$, and 373.15$) \mathrm{K}$, and the ones presented by Alptekin and Canakci [10] at $288.15 \mathrm{~K}$, all data at atmospheric pressure (vd Fig. 1). Taking linear representations of density data on the temperature obtained for the present work and data presented by Nogueira et al. [40], calculated deviations were between $0.1 \%$ and $0.4 \%$. No explanation was found for the differences between our values and those presented by Nogueira et al., since the measurement techniques were similar, and the FAMEs profile of the samples were almost the same resulting in comparable molecular weights (PCS: $M=287.53$, Nogueira et al.: $M=288.33$ ) and degrees of unsaturation (PCS: $D U=121.1$, Nogueira et al.: $D U=129.7$ ).

\subsection{Density correlation}

In the present work the GMA EoS was used to correlate density with temperature and pressure of cottonseed and all the other biodiesels in the database built for this work. The GMA EoS is conveniently given by [39],

$(2 z-1) V_{m}^{3}=A(T)+B(T) \rho_{m}$

where $z, V_{m}$, and $\rho_{m}$ are the compressibility factor, molar volume, and molar density, respectively. The temperature dependent parameters $A(T)$ and $B(T)$ are given by the following equations [39]:

$A(T)=A_{0}-\frac{2 A_{1}}{R T}+\frac{2 A_{2} \ln T}{R}$

$B(T)=B_{0}-\frac{2 B_{1}}{R T}+\frac{2 B_{2} \ln T}{R}$

where $A_{0}-A_{2}$ and $B_{0}-B_{2}$ are the fitting parameters, and $R$ is the gas constant. Density at different temperatures and pressures was calculated from

$B(T) \rho_{m}^{5}+A(T) \rho_{m}^{4}+\rho_{m}-2 p / R T=0$

The coefficients $A_{0}-A_{2}$ and $B_{0}-B_{2}$ of the GMA EoS regressed by fitting Eqs. (2)-(4) to the $p V T$ data through least-squares method Lavenberg-Marquardt method with confidence limits of $95 \%$ are given in Table 4. Standard deviation, $\sigma$, correlation coefficient $r$, number of data points $N_{p}$, are also indicated. The average relative deviation, 
Table 2

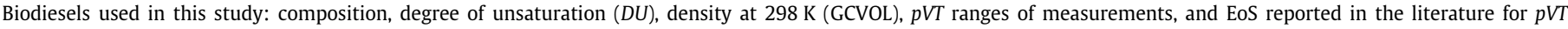
correlation.

\begin{tabular}{|c|c|c|c|c|c|c|c|c|c|c|c|}
\hline FAME & $S$ & $\mathrm{R}$ & $\mathrm{P}$ & SR & PR & SP & SRP & N5 & N6 & N7 & N8 \\
\hline C10 & 0 & 0.01 & 0.03 & 0 & 0.02 & 0.01 & 0.01 & 0 & 0 & 0 & 0 \\
\hline C12 & 0 & 0.04 & 0.24 & 0.03 & 0.2 & 0.18 & 0.14 & 0 & 0 & 0 & 0 \\
\hline C14 & 0.07 & 0.07 & 0.57 & 0.09 & 0.54 & 0.01 & 0.38 & 3.0 & 0 & 0 & 0 \\
\hline C16 & 10.76 & 5.22 & 42.45 & 8.9 & 23.09 & 25.56 & 18.97 & 6.5 & 1.4 & 7.4 & 38.6 \\
\hline C16:1 & 0.07 & 0.2 & 0.13 & 0.15 & 0.17 & 0.11 & 0.14 & 4.1 & 0 & 0 & 0 \\
\hline C17:0 & 0 & 0 & 0 & 0 & 0 & 0 & 0 & 1.5 & 0 & 0 & 0 \\
\hline C18 & 3.94 & 1.62 & 4.02 & 2.76 & 3.02 & 4.04 & 3.28 & 1.9 & 0.7 & 3.7 & 44.1 \\
\hline C18:1 & 22.96 & 62.11 & 41.92 & 41.82 & 52.92 & 33.13 & 42.51 & 64.8 & 5.2 & 24.8 & 4.8 \\
\hline C18:2 & 53.53 & 21.07 & 9.8 & 37.51 & 15.47 & 31.72 & 27.93 & 9.1 & 86.5 & 2.9 & 2.4 \\
\hline C18:3 & 7.02 & 6.95 & 0.09 & 7.02 & 3.08 & 3.58 & 4.66 & 9.0 & 6.2 & 61.2 & 10.1 \\
\hline $\mathrm{C} 20$ & 0.38 & 0.6 & 0.36 & 0.46 & 0.49 & 0.39 & 0.45 & 0 & 0 & 0 & 0 \\
\hline C20:1 & 0.23 & 1.35 & 0.15 & 0.68 & 0.67 & 0.2 & 0.52 & 0 & 0 & 0 & 0 \\
\hline $\mathrm{C} 22$ & 0.8 & 0.35 & 0.09 & 0.46 & 0.24 & 0.32 & 0.33 & 0 & 0 & 0 & 0 \\
\hline $\mathrm{C} 22: 1$ & 0.24 & 0.19 & 0 & 0.12 & 0.09 & 0.12 & 0.14 & 0 & 0 & 0 & 0 \\
\hline $\mathrm{C} 24$ & 0 & 0.22 & 0.15 & 0 & 0 & 0.63 & 0.53 & 0 & 0 & 0 & 0 \\
\hline$D U$ & 144.6 & 120.0 & 62.0 & 131.8 & 91.0 & 104.2 & 108.5 & 105.1 & 190.6 & 153.0 & 29.8 \\
\hline$\rho_{m, \mathrm{GVOL}}^{298}$ & 3.0037 & 2.9721 & 3.0652 & 2.9929 & 3.0198 & 3.0277 & 3.0114 & 3.0127 & 3.0044 & 3.0325 & 3.0372 \\
\hline$M$ & 292.77 & 295.08 & 284.32 & 293.43 & 289.49 & 289.20 & 290.86 & 290.79 & 294.1 & 291.97 & 286.26 \\
\hline$T_{\min }$ & 283.15 & 283.15 & 283.15 & 283.15 & 283.15 & 283.15 & 283.15 & 293.15 & 293.15 & 293.15 & 313.15 \\
\hline$T_{\max }$ & 333.15 & 333.15 & 333.15 & 333.15 & 333.15 & 333.15 & 333.15 & 373.15 & 373.15 & 373.15 & 373.15 \\
\hline$p_{\min }$ & 0.1 & 0.1 & 0.1 & 0.1 & 0.1 & 0.1 & 0.1 & 0.1 & 0.1 & 0.1 & 0.1 \\
\hline$p_{\max }$ & 45.0 & 45.0 & 45.0 & 45.0 & 45.0 & 45.0 & 45.0 & 34.5 & 34.5 & 34.5 & 34.5 \\
\hline$\rho_{\min }$ & 857.1 & 855.2 & 848.2 & 854.9 & 849.7 & 850.8 & 851.6 & 820.8 & 833.1 & 838.2 & 821.4 \\
\hline$\rho_{\max }$ & 916.0 & 913.8 & 907.4 & 913.6 & 909.1 & 909.9 & 911.0 & 897.7 & 909.6 & 914.9 & 884.8 \\
\hline EoS & Tait & Tait & Tait & Tait & Tait & Tait & Tait & TVG & TVG & TVG & TVG \\
\hline FAME & N9 & N17 & N19 & $\mathrm{N} 20$ & N21 & $\mathrm{N} 23$ & PCS & $\mathrm{SCHB}$ & & & \\
\hline C10 & 0 & 0 & 0 & 0 & 0 & 0 & 0 & 0 & & & \\
\hline $\mathrm{C} 12$ & 0 & 0 & 0.1 & 0 & 0 & 0.1 & 0 & 0 & & & \\
\hline C14 & 0 & 0 & 1.5 & 0 & 0.1 & 3.4 & 0.93 & 0.5 & & & \\
\hline C16 & 20.9 & 15.2 & 25.5 & 4.0 & 11.0 & 26.3 & 26.76 & 7.9 & & & \\
\hline C16:1 & 0 & 0 & 3.2 & 0.2 & 0.1 & 3.5 & 0 & 0.2 & & & \\
\hline C17:0 & 0 & 0 & 0.5 & 0 & 0 & 1.6 & 0 & 0 & & & \\
\hline C18 & 28.2 & 5.3 & 12.6 & 1.9 & 4.0 & 22.3 & 2.81 & 2.2 & & & \\
\hline C18:1 & 15.3 & 57 & 46.3 & 65.4 & 23.4 & 39.9 & 17.89 & 58.6 & & & \\
\hline C18:2 & 7.7 & 22.5 & 10.2 & 19.1 & 53.2 & 2.3 & 51.61 & 20.6 & & & \\
\hline C18:3 & 28.0 & 0 & 0.1 & 9.4 & 7.8 & 0.6 & 0 & 8.1 & & & \\
\hline $\mathrm{C} 20$ & 0 & 0 & 0 & 0 & 0 & 0 & 0 & 0.5 & & & \\
\hline C20:1 & 0 & 0 & 0 & 0 & 0 & 0 & 0 & 1.1 & & & \\
\hline $\mathrm{C} 22$ & 0 & 0 & 0 & 0 & 0 & 0 & 0 & 0.1 & & & \\
\hline C22:1 & 0 & 0 & 0 & 0 & 0 & 0 & 0 & 0.1 & & & \\
\hline $\mathrm{C} 24$ & 0 & 0 & 0 & 0 & 0 & 0 & 0 & 0.1 & & & \\
\hline$D U$ & 86.7 & 102.0 & 70.1 & 122.6 & 145.5 & 49.2 & 121.1 & 117.4 & & & \\
\hline$\rho_{m, \mathrm{GVOL}}^{298}$ & 3.0218 & 2.9973 & 3.0346 & 2.9789 & 3.0124 & 3.0422 & 3.0494 & 2.9854 & & & \\
\hline$M$ & 289.95 & 291.88 & 287.39 & 294.57 & 291.99 & 286.09 & 287.53 & 293.75 & & & \\
\hline$T_{\min }$ & 293.15 & 293.15 & 293.15 & 293.15 & 293.15 & 293.15 & 288.15 & 288.12 & & & \\
\hline$T_{\max }$ & 373.15 & 373.15 & 373.15 & 373.15 & 373.15 & 373.15 & 358.15 & 396.76 & & & \\
\hline$p_{\min }$ & 0.1 & 0.1 & 0.1 & 0.1 & 0.1 & 0.1 & 0.1 & 0.4 & & & \\
\hline$p_{\max }$ & 34.5 & 34.5 & 34.5 & 34.5 & 34.5 & 34.5 & 30.0 & 129.8 & & & \\
\hline$\rho_{\min }$ & 827.8 & 827.8 & 817.4 & 820.6 & 824.9 & 813.2 & 837.2 & 802.9 & & & \\
\hline$\rho_{\max }$ & 903.5 & 902.9 & 893.5 & 898.6 & 900.5 & 890.0 & 899.7 & 938.5 & & & \\
\hline EoS & TVG & TVG & TVG & TVG & TVG & TVG & - & - & & & \\
\hline
\end{tabular}

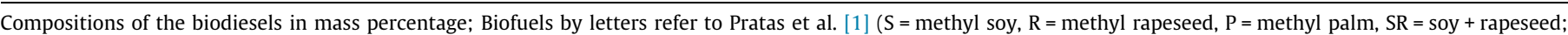

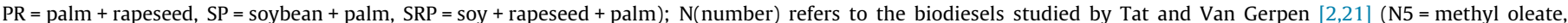

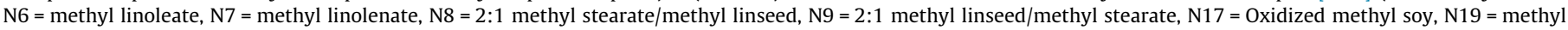

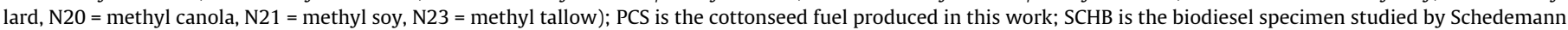
et al. [27]. $\rho_{m, G V O L}^{298} /\left(\mathrm{mol} \mathrm{dm}^{-3}\right) ; M /\left(\mathrm{g} \mathrm{mol}^{-1}\right) ; T / \mathrm{K} ; p / \mathrm{MPa} ; \rho /\left(\mathrm{kg} \mathrm{m}^{-3}\right)$. TVG: Empirical EoS by Tat and Van Gerpen [21].

$A R D$, and the standard deviation for density, $\sigma_{\rho}$, calculated respectively by

$A R D \%=100 \sum_{i=1}^{N_{p}}\left|1-\rho_{\text {calc }} / \rho_{\exp }\right|_{i} / N_{p}$

and

$\sigma_{\rho}=\left[\sum_{i=1}^{N_{p}}\left(\rho_{\text {cal }}-\rho_{\text {exp }}\right)_{i}^{2} /\left(N_{p}-k\right)\right]^{1 / 2}$ are also presented in Table 4. In Eqs. (6) and (7), $\rho_{\text {cal }}$ and $\rho_{\text {exp }}$ are the densities calculated from Eq. (5) and those experimentally determined for the measurement $i$, respectively, and $k(=6)$ is the number of adjusted parameters. The statistical indicators allowed to conclude that GMA EoS gives an excellent $p V T$ data correlation for biodiesels, since the standard deviation in density is generally less than $0.2 \mathrm{~kg} \mathrm{~m}^{-3}$ and the ARD is less than $0.02 \%$.

Under isothermal conditions, the quantity $(2 z-1) V_{m}^{3}$ showed a linear behavior with the molar density. The isotherms of $(2 z-1) V_{m}^{3}$ versus molar density are presented in Fig. 2 for cotton- 
Table 3

Experimental values of density data $(\rho)$, for cottonseed biodiesel as a function of temperature $(T)$, and pressure $(p)$.

\begin{tabular}{|c|c|c|c|c|c|c|c|c|}
\hline \multirow[t]{2}{*}{$p^{c}(\mathrm{MPa})$} & \multicolumn{8}{|c|}{$\rho^{\mathrm{a}}\left(\mathrm{kg} \mathrm{m}^{-3}\right)$ at $T^{\mathrm{b}}(\mathrm{K})$} \\
\hline & 288.15 & 298.15 & 308.15 & 318.15 & 328.15 & 338.15 & 348.15 & 358.15 \\
\hline 0.1 & 884.1 & 877.6 & 871.1 & 864.4 & 857.7 & 851.0 & 844.1 & 837.2 \\
\hline 1.0 & 884.6 & 878.2 & 871.6 & 865.0 & 858.3 & 851.6 & 844.8 & 837.9 \\
\hline 2.0 & 885.1 & 878.7 & 872.2 & 865.7 & 859.0 & 852.3 & 845.5 & 838.7 \\
\hline 3.0 & 885.7 & 879.3 & 872.9 & 866.3 & 859.7 & 853.1 & 846.3 & 839.5 \\
\hline 4.0 & 886.2 & 879.9 & 873.5 & 867.0 & 860.4 & 853.8 & 847.0 & 840.3 \\
\hline 5.0 & 887.3 & 880.9 & 874.5 & 867.9 & 861.3 & 854.6 & 847.9 & 841.0 \\
\hline 6.0 & 887.4 & 881.1 & 874.7 & 868.3 & 861.8 & 855.2 & 848.6 & 841.8 \\
\hline 7.0 & 887.9 & 881.7 & 875.3 & 868.9 & 862.5 & 855.9 & 849.3 & 841.8 \\
\hline 8.0 & 888.5 & 882.3 & 876.0 & 869.6 & 863.1 & 856.6 & 850.0 & 842.6 \\
\hline 9.0 & 889.0 & 882.8 & 876.5 & 870.2 & 863.8 & 857.3 & 850.7 & 843.4 \\
\hline 10.0 & 889.6 & 883.4 & 877.1 & 870.8 & 864.4 & 858.0 & 851.4 & 844.1 \\
\hline 15.0 & 892.2 & 886.1 & 880.0 & 873.9 & 867.6 & 861.3 & 854.9 & 848.4 \\
\hline 20.0 & 894.8 & 888.9 & 882.9 & 876.8 & 870.7 & 864.5 & 858.2 & 851.8 \\
\hline 25.0 & 897.2 & 891.4 & 885.6 & 879.6 & 873.6 & 867.5 & 861.4 & 855.2 \\
\hline 30.0 & 899.7 & 894.0 & 888.3 & 882.4 & 876.5 & 870.5 & 864.4 & 858.3 \\
\hline
\end{tabular}

a $U(\rho)<1.6 \mathrm{~kg} \mathrm{~m}^{-3}$.

b $U(T)=0.02 \mathrm{~K}$.

c $U(p)=0.02 \mathrm{MPa}$.
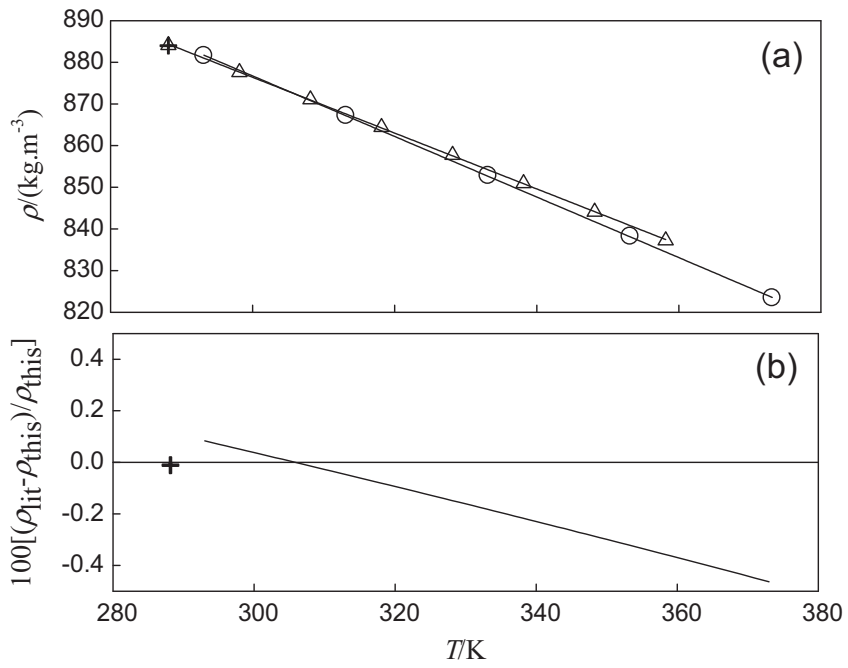

Fig. 1. Comparison between the densities of this work with values from the literature. (a) $\Delta$, this work; $\bigcirc$, Nogueira et al. [40]; +, Alptekin and Canakci [10]. (b) Deviations between the densities of this work $\left(\rho_{\text {this }}\right)$ and values from the literature $\left(\rho_{\text {lit }}\right)$. The line show the deviations from density of Nogueira et al. [40] taking linear representations of data.

seed and Schedemann et al. [27] biodiesels selected from our database, having in consideration the differences in temperature and pressure ranges at which density measurements were made. The linearity holded well for all isotherms and was slightly improved when shorter temperature and pressure ranges were considered like in the cottonseed case. Good results were also obtained for the other biodiesels from our database. The linearity seem to be very important for safe extrapolation of density at high temperatures and pressures.

Proceeding with the evaluation of the GMA EoS capacity to correlate the density data for all temperatures and pressures, the relative deviations between experimental and calculated values with Eq. (2) were evaluated. In Fig. 3, the relative deviation as a function of temperature and pressure is shown for cottonseed and Schedemann biodiesels. Due to more restricted temperature and pressure ranges of the fitting for cottonseed biodiesel the relative deviations were very small, usually in the range $\pm 0.02 \%$ (less than $\pm 0.2 \mathrm{~kg} \mathrm{~m}^{-3}$ ), while for the biofuel measured by Schedemann et al. [27] the deviations were usually less than $\pm 0.05 \%$ (less than $\pm 0.5 \mathrm{~kg} \mathrm{~m}^{-3}$ ). For the other biodiesels in our database the deviations were in the same range as found for cottonseed biodiesel.

The relative deviations in density resulting from correlation with the GMA EoS for all the biodiesels in the database at considered temperatures and pressures are given as supplementary material.

\subsection{Density prediction}

\subsubsection{The group contribution methods (GCVOL)}

A group contribution method (GCVOL) for the prediction of liquid densities as a function of temperature from the triple point to the normal boiling point was presented by Elbro et al. [53]. In that method (original GCVOL) the molar volume was calculated by

$V_{m}=\sum_{i} n_{i} \Delta v_{i}$

where $n_{i}$ is the number of group $i$ in the substance and $\Delta v_{i}$ is a temperature dependent group molar volume given by

$\Delta v_{i}=A_{i}+B_{i} T+C_{i} T^{2}$

where the group volume parameters $A_{i}, B_{i}$, and $C_{i}$ were obtained by Elbro et al. [53], whose original model presented 36 different group parameters for a large variety of chemical substances, including alkanes, alkenes, aromatic, alcohols, ketones, aldehydes, esters, ethers, chlorides, and siloxanes. The densities for strongly polar solvents were predicted by this method with an average relative deviation of $1 \%$ approximately.

In 2003, Ihmels and Gmehling [54] added 24 new groups to the 36 existing ones using the Dortmund Data Bank for Pure Component Properties (DDB-Pure). With this extension (extended GCVOL) densities of tertiary alcohols, alkynes, carboxylic acids, allenes, cycloalkanes, fluorides, bromides, iodides, thiols, sulfides, sulfates, amines, nitriles, and nitro compounds were calculated with an average mean deviation of $1.5 \%$ for a database of 1040 compounds. Pratas et al. [55,56] applied the original CGVOL to density prediction of pure FAMEs present in biodiesel in greater content, and those existing in minority. They concluded that for the majority FAMEs the density can be predicted within an ARD of $0.5 \%$, except for the methyl linoleate since the model describes poorly the effect of unsaturation on density. For the case of minority FAMEs and FAEEs the density could be predicted within a deviation of $1.5 \%$, except for the linolenate esters at high temperatures, again due 
Table 4

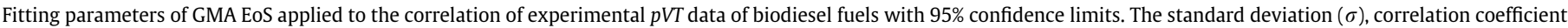
$(r)$, and number of data points $\left(N_{p}\right)$ are given. Also referred are the standard deviation in density $\left(\sigma_{\rho}\right)$, and the average relative deviation in density $(A R D)$.

\begin{tabular}{|c|c|c|c|c|c|c|c|c|}
\hline Parameter & $\mathrm{R}$ & $\mathrm{P}$ & $\mathrm{S}$ & SR & PR & SP & SRP & N5 \\
\hline$A_{0}{ }^{\mathrm{a}}$ & 156.6408 & 155.02365 & -191.31330 & -203.12707 & -19.90696 & 88.19071 & -76.56096 & -11.65220 \\
\hline$A_{1}{ }^{\mathrm{b}}$ & 57.4777 & 54.62277 & -9.48038 & -10.92667 & 21.34827 & 43.52531 & 12.35306 & 23.78009 \\
\hline $\mathrm{A}_{2}{ }^{\mathrm{c}}$ & -0.0916 & -0.090737 & 0.1232171 & 0.1308369 & 0.0167058 & -0.0490859 & 0.0525300 & 0.0121614 \\
\hline$B_{0}{ }^{d}$ & -49.4897 & -44.08269 & 69.27326 & 74.10448 & 12.63065 & -22.26999 & 32.08480 & 10.02161 \\
\hline$B_{1}{ }^{e}$ & -17.4004 & -15.45037 & 5.47409 & 6.09774 & -4.71302 & -11.88194 & -1.60108 & -5.56848 \\
\hline$B_{2}{ }^{\mathrm{f}}$ & 0.029599 & 0.026243 & -0.043751 & -0.046842 & $-8.56398 \times 10^{-3}$ & 0.012664 & -0.020847 & $-7.164697 \times 10^{-3}$ \\
\hline$\sigma^{\mathrm{g}}$ & 0.001653 & 0.000960 & 0.001426 & 0.001633 & 0.000928 & 0.000918 & 0.002572 & 0.001888 \\
\hline$\sigma_{\rho}^{\mathrm{h}}$ & 0.09 & 0.06 & 0.13 & 0.14 & 0.06 & 0.06 & 0.15 & 0.14 \\
\hline$r$ & 0.9993 & 1.0000 & 0.9999 & 0.9999 & 1.0000 & 1.0000 & 0.9997 & 0.9999 \\
\hline$N_{p}$ & 84 & 84 & 84 & 84 & 84 & 84 & 84 & 30 \\
\hline$A R D \%$ & 0.008 & 0.006 & 0.013 & 0.013 & 0.005 & 0.005 & 0.010 & 0.012 \\
\hline Parameter & N6 & N7 & N8 & N9 & N17 & N19 & N20 & N21 \\
\hline$A_{0}$ & 130.32820 & -28.91800 & 117.74356 & 230.08141 & -365.23193 & 146.2366 & -12.2901 & 168.1241 \\
\hline$A_{1}$ & 51.95599 & 19.70029 & 49.70914 & 74.50985 & -45.43698 & 54.5771 & 25.0475 & 60.8676 \\
\hline$A_{2}$ & -0.074832 & 0.0226279 & -0.0664370 & -0.1343981 & 0.2292324 & -0.0846 & 0.0128 & -0.0974 \\
\hline$B_{0}$ & -35.802429 & 18.70439 & -29.83708 & -65.78690 & 136.99403 & -39.8071 & 10.7011 & -49.1615 \\
\hline$B_{1}$ & -14.65893 & -3.54271 & -13.51784 & -21.47494 & 19.30164 & -15.2526 & -5.9416 & -17.7889 \\
\hline$B_{2}$ & 0.0209081 & -0.012448 & 0.017005 & 0.038765 & -0.085119 & 0.023366 & $-7.6505 \mathrm{e} \times 10^{-3}$ & 0.028891 \\
\hline$\sigma$ & 0.001772 & 0.002621 & 0.002117 & 0.002045 & 0.005443 & 0.001481 & 0.001989 & 0.001553 \\
\hline$\sigma_{\rho}^{\mathrm{h}}$ & 0.14 & 0.22 & 0.16 & 0.14 & 0.39 & 0.12 & 0.73 & 0.11 \\
\hline$r$ & 0.9999 & 0.9995 & 0.9997 & 0.9998 & 0.9989 & 0.9999 & 0.9999 & 0.9999 \\
\hline$N_{p}$ & 30 & 30 & 24 & 30 & 30 & 30 & 30 & 30 \\
\hline$A R D \%$ & 0.011 & 0.018 & 0.014 & 0.012 & 0.032 & 0.010 & 0.064 & 0.009 \\
\hline Parameter & N23 & PCS & $\mathrm{SCHB}$ & & & & & \\
\hline$A_{0}$ & 112.1672 & 93.75307 & 31.96439 & & & & & \\
\hline$A_{1}$ & 47.5108 & 45.51811 & 34.23931 & & & & & \\
\hline$A_{2}$ & -0.0637 & -0.05195 & -0.014476 & & & & & \\
\hline$B_{0}$ & -28.5269 & -25.7089 & -4.14103 & & & & & \\
\hline$B_{1}$ & -12.9304 & -12.9335 & -8.94477 & & & & & \\
\hline$B_{2}$ & 0.016435 & 0.014473 & 0.0015429 & & & & & \\
\hline$\sigma$ & 0.003008 & 0.001458 & 0.005861 & & & & & \\
\hline$\sigma_{\rho}^{\mathrm{h}}$ & 0.22 & 0.10 & 0.37 & & & & & \\
\hline$r$ & 0.9997 & 0.9998 & 0.9998 & & & & & \\
\hline$N_{p}$ & 30 & 120 & 324 & & & & & \\
\hline$A R D \%$ & 0.018 & 0.007 & 0.033 & & & & & \\
\hline
\end{tabular}

$A_{0}\left(\mathrm{dm}^{9} \mathrm{~mol}^{-3}\right)$.

b $A_{1}\left(\mathrm{MPa} \mathrm{dm}{ }^{12} \mathrm{~mol}^{-4}\right)$.

c $A_{2}\left(\mathrm{MPa} \mathrm{dm}{ }^{12} \mathrm{~mol}^{-4} \mathrm{~K}^{-1}\right)$.

${ }^{\mathrm{d}} B_{0}\left(\mathrm{dm}^{12} \mathrm{~mol}^{-4}\right)$.

e $B_{1}\left(\mathrm{MPa} \mathrm{dm}{ }^{15} \mathrm{~mol}^{-5}\right)$.

${ }^{\mathrm{f}} B_{2}\left(\mathrm{MPa} \mathrm{dm}{ }^{15} \mathrm{~mol}^{-5} \mathrm{~K}^{-1}\right)$

g $\sigma\left(\mathrm{dm}^{9} \mathrm{~mol}^{-3}\right)$.

$\sigma_{\rho}\left(\mathrm{kg} \mathrm{m}^{-3}\right)$.

to the poor description of the polyunsaturation effect on densities. Pratas et al. [36] also applied the original and the extended GCVOL models to 18 biodiesel samples of soy, rapeseed, palm, cottonseed, jatropha, and mixtures thereof at temperatures between 273.15 and $373.15 \mathrm{~K}$ and densities from 815 to $898 \mathrm{~kg} \mathrm{~m}^{-3}$, and obtained overall $A R D$ s of $0.6 \%$ and $2.7 \%$ for the original and the extended GCVOL, respectively. To solve the precision lack for the polyunsaturation ester effect, Pratas et al. [36] found new parameter values $A_{i}, B_{i}$, and $C_{i}$ relative to the double bond $(-\mathrm{CH}=)$ contribution, based on density data measured for FAMEs [55,56]. This revised variant of GCVOL was applied to the 18 biodiesels leading to a decrease in the overall $A R D$ s to $0.25 \%$ in density, corresponding to $\approx 2 \mathrm{~kg} \mathrm{~m}^{-3}$ [36]. Pratas et al. extended the revised GCVOL to high pressures using the equation [36]

$\rho(T, p)=\frac{M}{V_{m}(T)(1+A p)}$

where $\rho$ is the density in $\mathrm{g} \mathrm{cm}^{-3}, M$ is the molecular weight in $\mathrm{g} \mathrm{mol}^{-1}, V_{m}(T)$ is the molar volume in $\mathrm{cm}^{3} \mathrm{~mol}^{-1}$ predicted by revised GCVOL, and $p$ is the absolute pressure (MPa). For biodiesel the mean molecular mass is
$M=\sum_{i} x_{i} M_{i}$

where $x_{i}$ and $M_{i}$ are the molar fraction and the molecular weight of FAME $i$ in the fuel, respectively. Pratas et al. obtained $A=-5.7 \times 10^{-4} \mathrm{MPa}^{-1}$ [36] by fitting Eq. (10) to high pressure densities for laurate, myristate, and oleate methyl esters, reported by Pratas et al. [55,56]. The Eq. (10) correlated the high pressure densities of these methyl esters with an ARD of $0.3 \%$, and the high pressure densities for 8 biodiesel fuels were predicted with $A R D$ s from $0.23 \%$ to $0.74 \%$ [36]. We have recalculated the constant $A$ in Eq. (10) by fitting densities of methyl palmitate [57], methyl oleate $[1,58]$, and methyl linoleate $[27,58]$, since they were the most abundant FAMEs in the biodiesels. The fitting of Eq. (10) gave $A=\left(-5.46 \times 10^{-4} \pm 4.35 \times 10^{-6}\right) \mathrm{MPa}^{-1}$ with standard deviation of $5.0 \mathrm{~kg} \mathrm{~m}^{-3}$ and $A R D=0.43 \%$.

The $A R D$ s resulting from application of Eq. (10) to the prediction of high-pressure densities for the nineteen biodiesels in the database are presented in Table 8. Some of the biodiesels measured by Tat and Van Gerpen as N7, N8, N9, N17 showed ARDs higher than $1 \%$. These biodiesels could be considered as outliers from the point of view of the dominant FAMEs profiles since N7 had a 

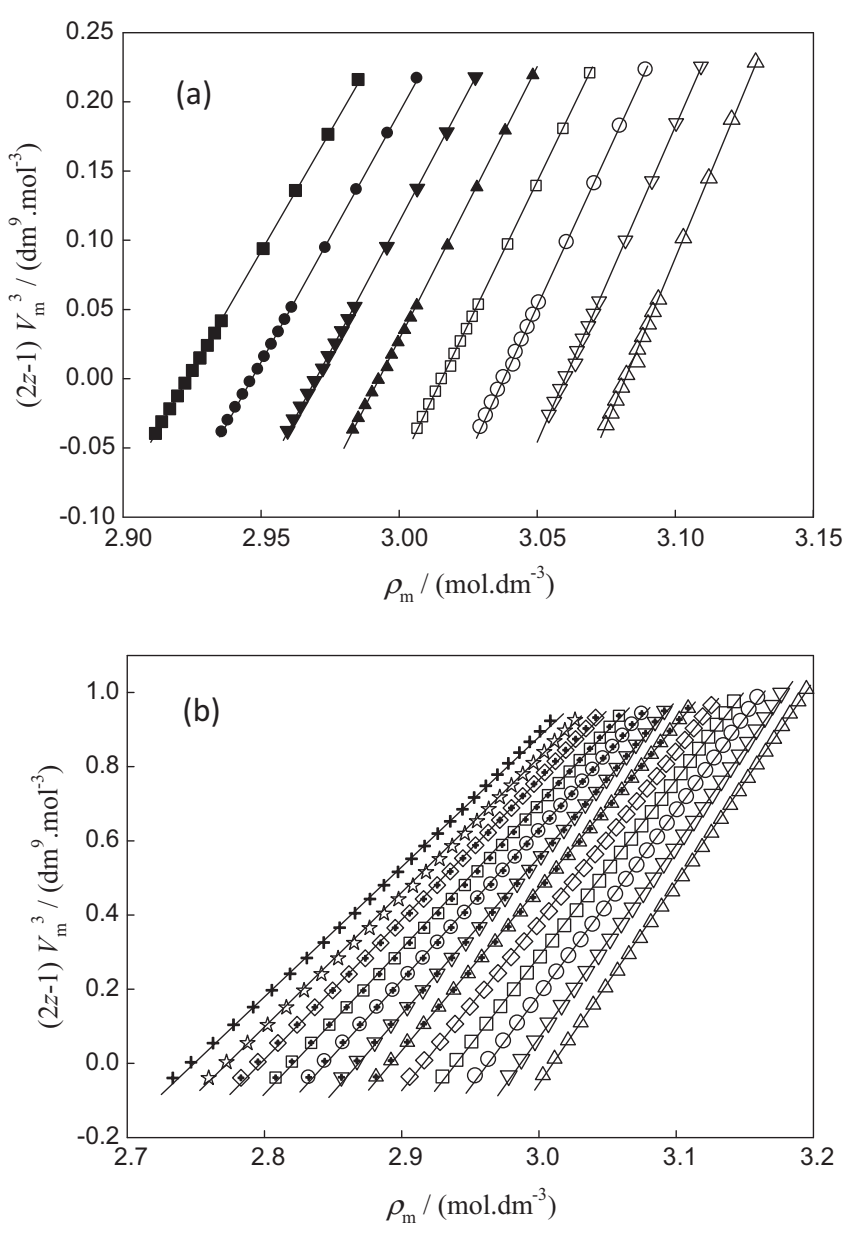

Fig. 2. Isotherms of $(2 z-1) V_{m}{ }^{3}$ versus the molar density $\left(\rho_{m}\right)$ for cottonseed and Shedmann (SCHB) biodiesels calculated from GMA EoS. (a) Cottonseed (experimental data of this work): $\Delta, 288.15 \mathrm{~K} ; \nabla, 298.15 \mathrm{~K} ; \bigcirc, 308.15 \mathrm{~K} ; \square, 318.15 \mathrm{~K} ; \boldsymbol{\Delta}$, $328.15 \mathrm{~K} ; \boldsymbol{\nabla}, 338.15 \mathrm{~K} ; \bullet$, $348.15 \mathrm{~K} ; \mathbf{\square}, 358.15 \mathrm{~K}$ (b) SCHB: $\Delta, 288.12 \mathrm{~K} ; \nabla, 297.93 \mathrm{~K} ;$ ○, $307.8 \mathrm{~K} ; \square, 317.6 \mathrm{~K} ; \diamond, 327.49 \mathrm{~K} ;$ A. $337.38 \mathrm{~K} ; \nabla, 347.26 \mathrm{~K} ;$ ๑), $357.13 \mathrm{~K} ;$ 田, $367.03 \mathrm{~K} ; \diamond, 376.91$; $\$, 386.84 \mathrm{~K} ;+$, $396.76 \mathrm{~K}$. Full curves calculated from correlation with GMA EoS.

very high C18:3 content, N8 and N9 showed high values of C18:0, and N17 presented a very high content of C18:1. The overall average deviation of $0.60 \%$ corresponding to about $5 \mathrm{~kg} \mathrm{~m}^{-3}$, can be regarded as an indicator of a reasonable performance in predicting the density with Eq. (10). A huge advantage of this method is its simplicity and straightforward density estimation. The detailed information about the deviations in density resulting from Eq. (10) applied to all the biodiesels in the built database is given as supplementary material.

\subsubsection{Degree of unsaturation}

The density data for several biodiesels measured by Pratas et al. [1] and by Tat and Van Gerpen [2,21] are represented in Fig. 4 as function of the degree of unsaturation for $293.15 \mathrm{~K}$ and $353.15 \mathrm{~K}$, at atmospheric pressure.

Clearly, for each temperature the density was a linear function of the $D U$. For this reason and taking into account that density is a linear function of temperature with a slight curvature at high pressures [23,27], the equation

$\rho=\left(d_{1}+d_{2} T+d_{3} p+d_{4} p^{2}\right)+\left(d_{5}+d_{6} T+d_{7} p+d_{8} p^{2}\right) D U$

is proposed to represent the biodiesel density within wide ranges of temperatures and pressures.

The biodiesels (S, R, P) reported by Pratas et al. [1] and (N6, N20, N23) studied by Tat and Van Gerpen [2,21] were used as the training set for fitting with Eq. (12), and the other thirteen biodiesels were included in the validation set. The training set was selected to fulfil the following: (i) biodiesels having a linear density dependence on $D U$; (ii) biodiesels covering a wide range of $D U$ (the range of $D U$ is between 49.2 (N23) and 190.6 (N6)); (iii) biodiesels from different authors should spread in wide density ranges. The parameters of Eq. (12) for $95 \%$ confidence limits were $d_{1}=(1088.017 \pm 3.359)$, $d_{2}=(-0.74348 \pm 0.01054), \quad d_{3}=(0.50665 \pm 0.06776), \quad d_{4}=(1.60$ $\left.74 \times 10^{-3} \pm 1.6572 \times 10^{-3}\right), \quad d_{5}=(0.02599 \pm 0.02719), \quad d_{6}=(2.7$ $\left.723 \times 10^{-4} \pm 8.485 \times 10^{-5}\right), \quad d_{7}=\left(8.8455 \times 10^{-4} \pm 5.6863 \times 10^{-4}\right)$, $d_{8}=\left(-2.1255 \times 10^{-5} \pm 1.4024 \times 10^{-5}\right)$ with correlation coefficient and standard deviation of 0.996 and $1.7 \mathrm{~kg} \mathrm{~m}^{-3}$, respectively. Eq. (12) gave overall $A R D$ s of $0.15 \%$ for the training set and $0.42 \%$ for the validation set. Detailed results for density calculations of all biodiesels are presented in Table 8 . The minimum $(A R D=0.09 \%)$ and the maximum $(A R D=1.09 \%)$ deviations in the validation set were observed in SR and N7 biodiesels, respectively. The overall average deviation of $0.42 \%$ corresponding to less than $4 \mathrm{~kg} \mathrm{~m}^{-3}$, can be regarded as a good indicator for the density prediction. Eq. (12) gives better density predictions than more complex methods, including those based in SAFT or CPA equations of state. The $A R D=0.42 \%$ obtained for the validation set was close to the value $0.49 \%$ reported by Oliveira et al. [34] with soft-SAFT EoS applied to density prediction of FAMEs and biodiesels measured by Pratas et al. [1]. Detailed information about deviations in density resulting from Eq. (12) applied to all biodiesels in the database is given as supplementary material.
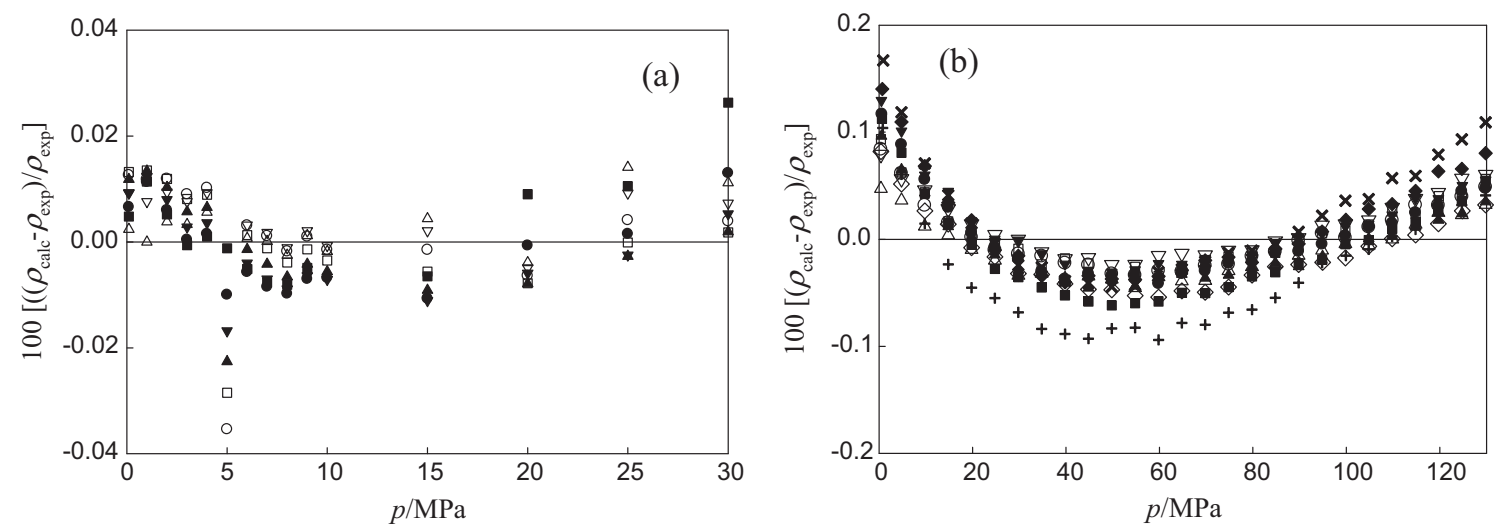

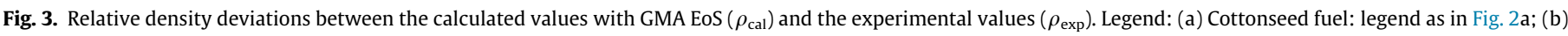

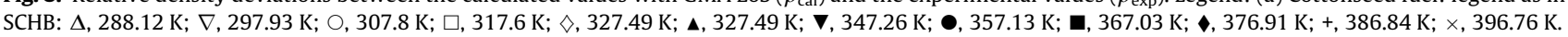




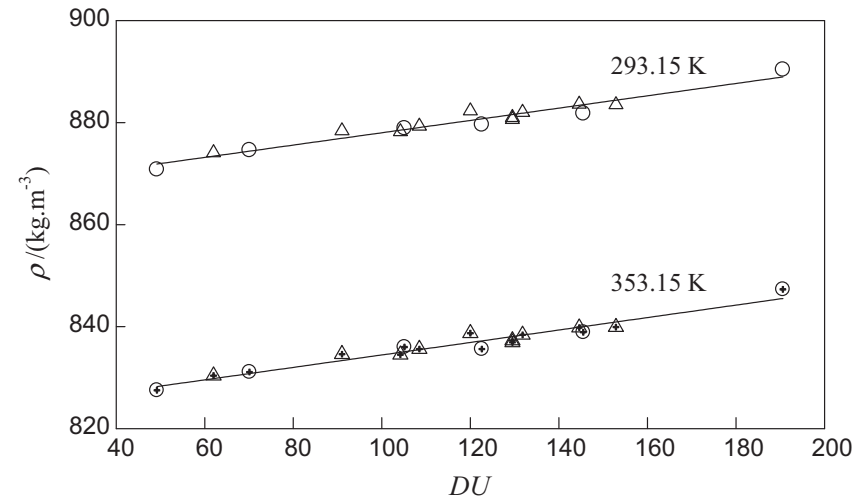

Fig. 4. Density as function of the degree of unsaturation for some biodiesels in the database. At $293 \mathrm{~K}$ and $0.1 \mathrm{MPa}: \Delta$, [1]; $O$, [2,21]; at $353 \mathrm{~K}$ and $0.1 \mathrm{MPa}: \mathbf{A}$, [1], (૯) $[2,21]$.

\subsubsection{Predictive GMA}

Taking the advantage of the large ranges of temperature and pressure available for the density data of Schedemann fuel (SCHB), we have evaluated the possibility of predicting plausible values for the density at temperatures and pressures significantly higher than the $(T, p)$ ranges used in the fitting of the GMA EoS. As the biodiesel density measurements have usually been made for temperatures lower than $373.15 \mathrm{~K}$ and pressures up to $50 \mathrm{MPa}$, the GMA EoS was tested under restrictive temperature and pressure ranges considering two approaches: (i) for $T=(288-357) \mathrm{K}$ and $p=(0.4-5)$ MPa; (ii) $T=(288-357) \mathrm{K}$ and $p=(0.4-50)$ MPa. This approach (i) was based on the fact that density measurements in some studies just were evaluated up to $5 \mathrm{MPa}$ [26]. We have concluded that this approach (i) gave good predictions of density for pressures up to $40 \mathrm{MPa}$ and temperatures up to $397 \mathrm{~K}$. With procedure (ii) it should be possible to extend the good prediction of density to higher temperatures and pressures. The density deviations were only about $3 \mathrm{~kg} \mathrm{~m}^{-3}$ near the maximum temperature $(T=397 \mathrm{~K})$
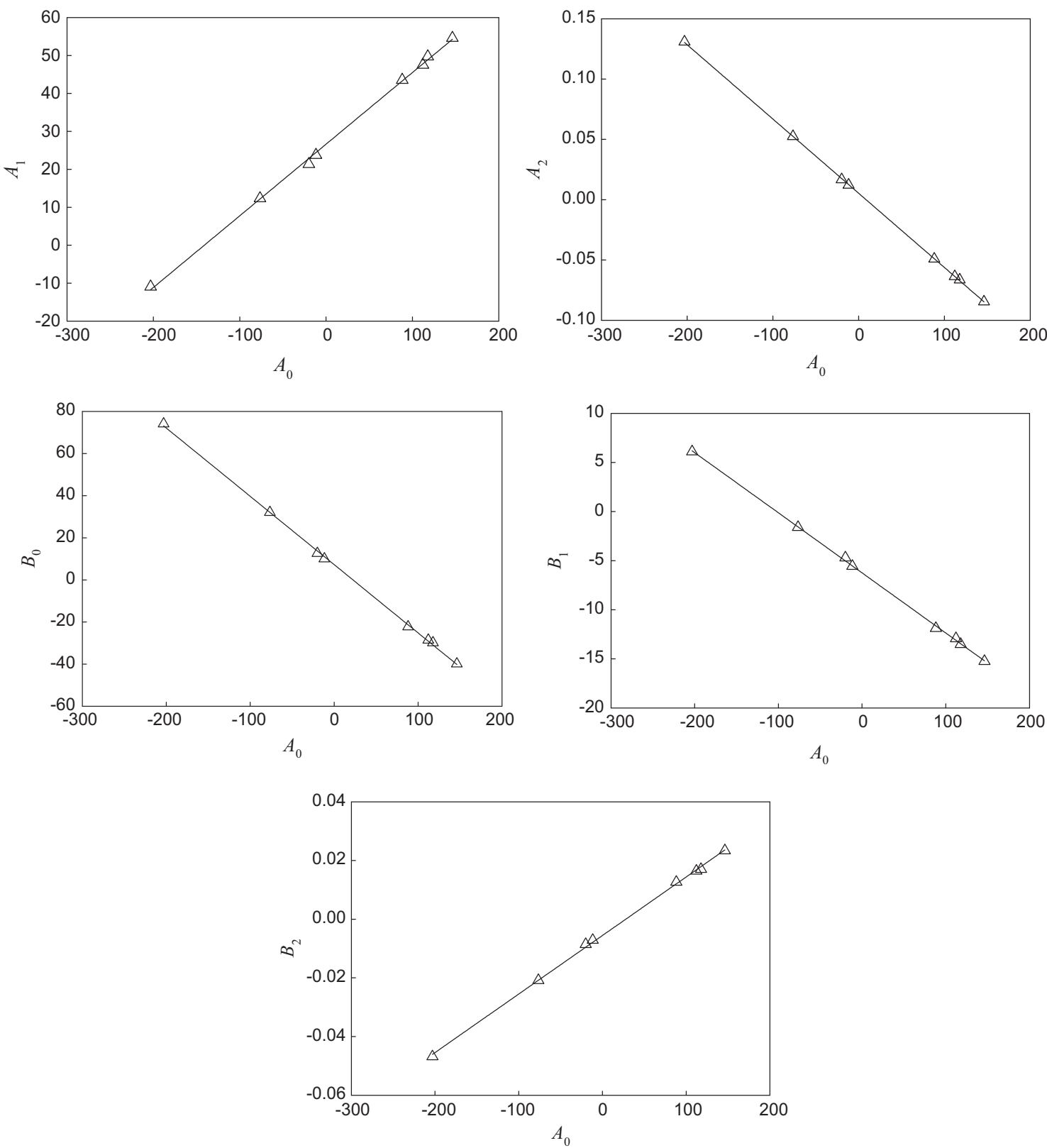

Fig. 5. Correlation between coefficients $A_{1}, A_{2}, B_{0}, B_{1}$ and $B_{2}$ of the GMA EoS with coefficient $A_{0}$ for biodiesels SR, SP, PR, SRP, N5, N8 N19, N23. 

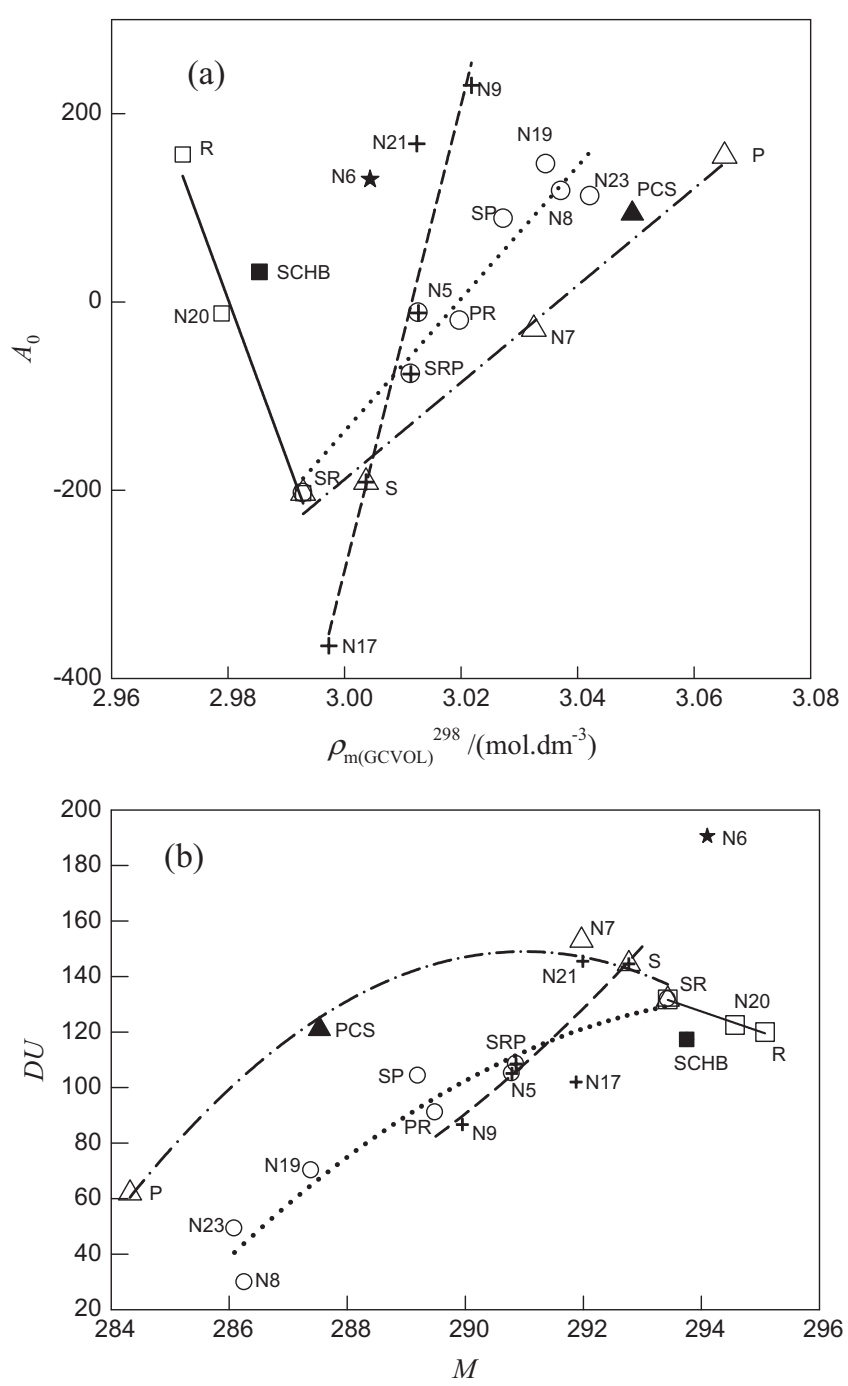

Fig. 6. Relations for predictive 4PGMA EoS. (a) Coefficient $A_{0}$ as function of the molar density at $298 \mathrm{~K}$ from the revised GCVOL model $\left(\rho_{m, 9 m}^{298}\right)$ : $\square$, path $1 ;+$, path 2 ; $\bigcirc$, path $3 ; \Delta$, path 4 . The lines represent Eq. (14): (-) path $1 ;(---)$ path $2 ;(\cdots)$ path 3; (-..-) path 4. (b) Degree of unsaturation parameter $(D U)$ as function of mean molar mass $(M)$ for the biodiesels studied. Lines correspond to the fittings with Eq. (16). Lines and symbols as in (a).

and pressure ( $p=130 \mathrm{MPa}$ ) and the predictions were in excellent agreement with the experimental values up to $75 \mathrm{MPa}$ even at $397 \mathrm{~K}$ (vd. Fig. S2).

These results are certainly important for density prediction in fuel injection and combustion simulations, specially in diesel engines operating at high pressure.

A new predictive method for the determination of biodiesel density as function of temperature and pressure was derived from GMA EoS using the following procedure. Starting with the fitted $A_{0}-A_{2}$ and $B_{0}-B_{2}$ parameters of biodiesel fuels studied by Pratas et al. [1] and by Tat and Van Gerpen [2,21] listed in Table 4, it was found that the parameters $A_{i}(i=1,2)$ and $B_{i}(i=0,2)$ were linear functions in $A_{0}$ as shown in Fig. 5. Thus, once $A_{0}$ is known all the other parameters follow. Next step, a correlation was established between $A_{0}$ and a fuel property of easy calculation, namely the molar density at $298.15 \mathrm{~K}$ obtained via GCVOL method, $\rho_{m, \mathrm{GVOL}}^{298}$, was calculated by

$\rho_{m, \mathrm{GVOL}}^{298}=\frac{M}{V_{m, \mathrm{GVOL}}^{298}}$

where $V_{m, \mathrm{GVOL}}^{298}$ is the biodiesel molar volume calculated from the revised GCVOL from Eqs. (8) and (9). It was found that

$A_{0}=A_{00}+A_{01} \rho_{m, \mathrm{GVOL}}^{298}$

For the selected biodiesels, a distribution following four paths in the $\left(\rho_{m, \mathrm{GVOL}}^{298}, A_{0}\right)$ plot was found as illustrated in Fig. 6a. It was also observed that three paths intercept close to the SR biodiesel position in the diagram. The coefficients $A_{00}, A_{01}$ and the corresponding correlation coefficients, and the standard deviations for the four paths are presented in Table 5. As mentioned before, the parameters $A_{i}(i=1,2)$ and $B_{i}(i=0,2)$ are linear functions of $A_{0}$. The linear plots for all paths are given as supplementary material in Figs. S3-S6. For each path $j(j=1,4)$, the coefficients $A_{i j}$ and $B_{i j}$ are linearly correlated with $A_{0 j}$ by the Eq. (15)

$\left(A_{i j}\right.$ or $\left.B_{i j}\right)=a_{i j}+b_{i j} A_{0 j}$

The intercepts $a_{i j}$ and slopes $b_{i j}$, for each path are given in Table 6 .

It was observed that the biodiesel $D U$ was related to the mean molar mass following also three paths with close interception in the SR position as shown in Fig. 6b. The biodiesels with lower molar mass, following path 3 , presented considerable lower degree of unsaturation compared with those having the same molar mass but following path 4 . The fuels in path 1 exhibited a linear $(D U, M)$ behavior while the other paths were parabolic. In path $2, D U$ increase strongly with the molar mass in the small range considered for this property and the representative line for this path crosses paths 3 and 4 . The fuels of path 2 have molar mass in the range $M=(289.95-292.77) \mathrm{g} \mathrm{mol}^{-1}$ corresponding to an average of $291.37 \pm 1.02 \mathrm{~g} \mathrm{~mol}^{-1}$. The corresponding degree of unsaturation as a function of molar mass is given by the general equation

$D U=d_{0}+d_{1} M+d_{2} M^{2}$

The parameters $d_{0}, d_{1}, d_{2}$ and the corresponding correlation coefficients and standard deviations for the paths 1-4 are given in Table 7.

The density prediction by GMA EoS considering the four paths (4PGMA) was made using the following criteria. From biodiesel composition, values of $D U, M$, and $\rho_{m, \mathrm{GVOL}}^{298}$ were calculated using Eqs. (1), (11) and (13). If the molar mass was in the range of $291.37 \pm 1.02 \mathrm{~g} \mathrm{~mol}^{-1}$ (path 2) or whether $2.970<\rho_{m, \mathrm{GVOL}}^{298}<2.993$ (path 1), Eqs. (14) and (15) were used. When $\rho_{m . G V L}^{298}>2.993$, Eq. (16) was used to evaluate $D U$ and this value was compared with the one from Eq. (1). Now the selection between paths 3 and 4 was made following the lower difference in $D U$. For biodiesels with high degree of unsaturation ( $D U>150$, such as N6) the use of path 2 should be used. Once the coefficients $A_{0}-A_{2}$ and $B_{0}-B_{2}$ were

Table 5

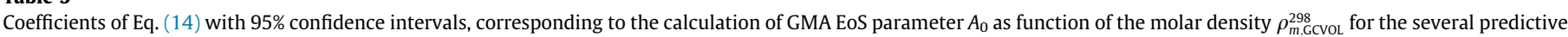
paths. The biodiesels used in each path are indicated for the paths.

\begin{tabular}{|c|c|c|c|c|}
\hline Path & $A_{00}$ & $A_{01}$ & $r$ & $\sigma$ \\
\hline $1(\mathrm{R}, \mathrm{SR}, \mathrm{N} 20)$ & $50126.241 \pm 8426.018$ & $-16819.896 \pm 2826.240$ & 0.986 & 42.18 \\
\hline 2 (S, SRP, N5, N9, N17, N21) & $-74576.7736 \pm 13663.295$ & $24763.645 \pm 4539.462$ & 0.939 & 85.55 \\
\hline 3 (SR, SP, PR, SRP, N5, N8, N19, N23) & $-21247.607 \pm 2458.569$ & $7036.696 \pm 813.476$ & 0.962 & 35.23 \\
\hline $4(\mathrm{P}, \mathrm{S}, \mathrm{SR}, \mathrm{N} 7)$ & $-15644.7775 \pm 1249.6898$ & $5152.0630 \pm 413.296$ & 0.994 & 23.297 \\
\hline
\end{tabular}


Table 6

Parameters $a$ and $b$ of each of coefficients $A_{1 j}, A_{2 j}, B_{0 j}, B_{1 j}, B_{2 j}$ with 95\% confidence limits, correlated linearly with $A_{0 j}$ in Eq. (15) for path $j$.

\begin{tabular}{|c|c|c|c|c|}
\hline Parameter & $j=1$ & $j=2$ & $j=3$ & $j=4$ \\
\hline \multicolumn{5}{|l|}{$A_{1 j}$} \\
\hline$a^{1 j}$ & 27.5906 & 27.6408 & 26.6213 & 25.7892 \\
\hline$b$ & 0.1901 & 0.1998 & 0.1888 & 0.18351 \\
\hline$\sigma$ & 0.2534 & 1.0627 & 0.8551 & 0.7416 \\
\hline$r$ & 1.000 & 1.000 & 0.999 & 1.000 \\
\hline \multicolumn{5}{|l|}{$A_{2 j}$} \\
\hline$a$ & $5.2303 \times 10^{-3}$ & $5.7578 \times 10^{-3}$ & $5.3296 \times 10^{-3}$ & $5.0017 \times 10^{-3}$ \\
\hline$b$ & $-6.1835 \times 10^{-4}$ & $-6.1173 \times 10^{-4}$ & $-6.1549 \times 10^{-4}$ & $-6.1840 \times 10^{-4}$ \\
\hline$\sigma$ & $8.916 \times 10^{-6}$ & 0.0005 & 0.0005 & 0.0003 \\
\hline$r$ & 1.000 & 1.000 & 1.000 & 1.000 \\
\hline \multicolumn{5}{|l|}{$B_{0 j}$} \\
\hline$a$ & 5.0461 & 8.3032 & 7.2557 & 7.5176 \\
\hline$b$ & -0.3433 & -0.3391 & -0.3243 & -0.32769 \\
\hline$\sigma$ & 1.7597 & 4.0022 & 0.9725 & 1.4906 \\
\hline$r$ & 1.000 & 0.999 & 1.000 & 1.000 \\
\hline \multicolumn{5}{|l|}{$B_{1 j}$} \\
\hline$a$ & -7.0268 & -6.3924 & -6.2496 & -5.8746 \\
\hline$b$ & $-6.5267 \times 10^{-2}$ & $-6.7720 \times 10^{-2}$ & $-6.1213 \times 10^{-2}$ & $-5.9914 \times 10^{-2}$ \\
\hline$\sigma$ & 0.3469 & 0.7927 & 0.1855 & 0.4970 \\
\hline$r$ & 1.000 & 0.999 & 1.000 & 0.999 \\
\hline \multicolumn{5}{|l|}{$B_{2 j}$} \\
\hline$a^{3}$ & $-4.1383 \times 10^{-3}$ & $-6.3474 \times 10^{-3}$ & $-5.5601 \times 10^{-3}$ & $-5.6124 \times 10^{-3}$ \\
\hline$b$ & $2.1232 \times 10^{-4}$ & $2.0743 \times 10^{-4}$ & $1.9945 \times 10^{-4}$ & $2.0255 \times 10^{-4}$ \\
\hline$\sigma$ & 0.0011 & 0.0025 & 0.0008 & 0.0009 \\
\hline$r$ & 1.000 & 0.999 & 1.000 & 1.000 \\
\hline
\end{tabular}

Table 7

Coefficients of Eq. (16) with 95\% confidence, corresponding to the calculation of degree of unsaturation as function of the molar mass for the paths in 4PGMA.

\begin{tabular}{|c|c|c|c|c|c|}
\hline Path & $d_{0}$ & $d_{1}$ & $d_{2}$ & $r$ & $\sigma$ \\
\hline $1(\mathrm{R}, \mathrm{SR}, \mathrm{N} 20)$ & 2275.27 & -7.306 & 0 & 0.996 & 0.8 \\
\hline $2(\mathrm{~S}, \mathrm{SRP}, \mathrm{N} 5, \mathrm{~N} 9, \mathrm{~N} 17, \mathrm{~N} 21)$ & 85989.44 & -609.23 & 1.0794 & 0.836 & 17.1 \\
\hline 3 (SR, SP, PR, SRP, N5, N8, N19, N23) & -94629.5 & 641.76 & -1.0865 & 0.968 & 10.2 \\
\hline $4(\mathrm{P}, \mathrm{S}, \mathrm{SR}, \mathrm{N} 7)$ & -168458.48 & 1158.86 & -1.9912 & 0.992 & 6.5 \\
\hline
\end{tabular}

calculated using Eqs. (14) and (15), the density came out from Eq. (5).

For predictive GMA, we have chosen the biodiesels (N6, PCS, SCHB) considered as forming a "true" validation set, because these biodiesels were not used in the development of the predictive method. The other biodiesels in database measured by Pratas et al. [1] and Tat and Van Gerpen [2,21] were considered to establish a linear correlation between coefficient $A_{0}$ and $\rho_{m, \mathrm{GVOL}}^{298}$ and linear $\left(A_{1}, A_{2}\right)$ and $\left(B_{0}-B_{2}\right)$ correlations with $A_{0}$. Nevertheless, all the biodiesels in our database could be broadly considered as belonging to a validation set of the predictive GMA, since their densities were not used directly in the fittings. The 4PGMA results are presented in Table 8 , and detailed information regarding the relative deviations in density resulting from the predictive 4PGMA model for all biodiesels in database, for all temperatures and pressures are given as supplementary material. With the exceptions of the biodiesels (N7, N8, N9) all ARD values for the biodiesels were lower than $0.35 \%$ (less than $3 \mathrm{~kg} \mathrm{~m}^{-3}$ ). The contour plots for the density differences as a function of temperature and pressure for the set (N6, PCS, SCHB) not included in 4PGMA development are presented in Fig. S7 given in supplementary material. The N6 fuel, essentially C18:1 (0.865 by mass) with the higher degree of unsaturation $(D U=191)$ presented the lower density deviations. However N6 had a composition far from that usually found in biodiesels. For PCS and SCHB biodiesels, the density deviations in predictions were low in the recommended $(p, T)$ values for operation of injection systems $(T \approx 344 \mathrm{~K}, p=12-22 \mathrm{MPa}$ ) [3-5]. For PCS biodiesel, the predicted densities at the recommended injection $(p, T)$ conditions were practically the measured ones. The maximum overall
ARD of only $0.25 \%\left(\approx 2 \mathrm{~kg} \mathrm{~m}^{-3}\right)$ obtained for path 1 indicated that 4PGMA could provide excellent density predictions at high pressure. The $p V T$ data presented by Schedemann in more extensive temperature and pressure ranges was predicted with $A R D=0.34 \%$. The 4PGMA provided much better predictions of density than SAFT and CPA equations of state, and requiring comparatively much less computation effort.

\subsection{Mechanical coefficients}

The thermal expansivity, $\alpha_{p}=-(1 / \rho)(\partial \rho / \partial T)_{p}$, and the isothermal compressibility, $k_{T}=(1 / \rho)(\partial \rho / \partial p)_{T}$ can be calculated from the GMA EoS as [59]:

$\alpha_{p}=\frac{\left(2 B_{1}+2 B_{2} T\right) \rho_{m}^{5}+\left(2 A_{1}+2 A_{2} T\right) \rho_{m}^{4}+2 p}{5 \rho_{m}^{5}\left(R T^{2} B_{0}-2 B_{1} T+2 B_{2} T^{2} \ln T\right)+4 \rho_{m}^{4}\left(R T^{2} A_{0}-2 A_{1} T+2 A_{2} T^{2} \ln T\right)+R T^{2} \rho_{m}}$

$k_{T}=\frac{2}{\rho_{m} R T+5 \rho_{m}^{5}\left(R T B_{0}-2 B_{1}+2 B_{2} T \ln T\right)+4 \rho_{m}^{4}\left(R T A_{0}-2 A_{1}+2 A_{2} T \ln T\right)}$

The internal pressure $p_{i}=(\partial U / \partial V)_{T}$, where $U$ is the internal energy, can be calculated according to the relationship

$p_{i}=(\partial U / \partial V)_{T}=T(\partial p / \partial T)_{V}-p=T \cdot \gamma_{V}-p$

where $\gamma_{V}$ is the thermal pressure coefficient $\left(\gamma_{V}=\alpha_{P} / k_{T}\right)$.

Based on the excellent results for the density description by the GMA EoS, thermal expansivity, isothermal compressibility, and internal pressure were calculated from Eqs. (17)-(19) at temperatures from $283.15 \mathrm{~K}$ to $373.15 \mathrm{~K}$ and pressures between $0.1 \mathrm{MPa}$ 
Table 8

Average relative deviation on density for the predictive methods applied to the biodiesels.

\begin{tabular}{llll}
\hline Biodiesel & Eq. (10) & Eq. $(12)$ & $\begin{array}{l}\text { 4PGMA EoS } \\
\text { ARD (path) }\end{array}$ \\
\hline S & 0.55 & $(0.06)^{\mathrm{a}}$ & $0.04(2) ; 0.03(4)$ \\
$\mathrm{R}$ & 0.61 & $(0.13)^{\mathrm{a}}$ & $0.19(1)$ \\
$\mathrm{P}$ & 0.49 & $(0.13)^{\mathrm{a}}$ & $0.21(4)$ \\
SR & 0.44 & 0.09 & $0.16(1) ; 0.04(3) ; 0.18(4)$ \\
PR & 0.34 & 0.12 & $0.02(3)$ \\
SP & 0.32 & 0.16 & $0.03(3)$ \\
SRP & 0.37 & 0.12 & $0.09(2) ; 0.02(3)$ \\
ARD & 0.45 & $0.12^{\mathrm{e}}$ & $0.18(1) ; 0.07(2), 0.03(3) ; 0.14(4)$ \\
N5 & 0.39 & 0.21 & $0.26(2) ; 0.13(3)$ \\
N7 & 1.15 & 1.09 & $0.48(4)$ \\
N8 & 1.30 & 1.05 & $0.70(3)$ \\
N9 & 1.07 & 0.84 & $0.59(2)$ \\
N17 & 1.15 & 0.56 & $0.22(2)$ \\
N19 & 0.38 & 0.25 & $0.14(3)$ \\
N20 & 0.29 & $(0.36)^{\mathrm{a}}$ & $0.31(1)$ \\
N21 & 0.34 & 0.36 & $0.31(2)$ \\
N23 & 0.32 & $(0.33)^{\mathrm{a}}$ & $0.34(3)$ \\
ARD & 0.71 & $0.62^{\mathrm{e}}$ & $0.35(2) ; 0.33(3)$ \\
N6 & 0.80 & $(0.12)^{\mathrm{a}}$ & $0.10(2)$ \\
PCS & 0.50 & 0.16 & $0.17(4)$ \\
SCHB & 0.67 & 0.50 & $0.34(1)$ \\
$A R D^{\mathrm{d}}$ & 0.66 & $0.33^{\mathrm{e}}$ & \\
OARD & 0.60 & $0.42^{\mathrm{e}}$ & $0.25(1) ; 0.23(2) ; 0.18(3) ; 0.21(4)$ \\
\hline
\end{tabular}

a Biodiesels used in the training set.

b Total ARD for the biodiesels from Pratas et al. [1].

c Total ARD for the biodiesels from Tat and Van Gerpen [21].

d Total ARD for the biodiesels N6 [2,21], cottonseed, and SCHB [27].

e $A R D$ for the subsets from the validation set.

f $O A R D=\sum_{i} A R D_{i} i=19$ for Eq. (10); $i=13$ for Eq. (12); $i=4$ for path $1 ; i=7$ for path $2 ; i=8$ for path $3 ; i=5$ for path 4 .

and $40 \mathrm{MPa}$ using the coefficients presented in Table 4 . The values of the mechanical coefficients for all biodiesels included in the database are given as supplementary material.

Density variations along isothermic or isobaric paths are usually smooth functions of temperature and pressure. However, the mechanical coefficients are quite sensitive to subtle changes in density. The pressure behavior of $\alpha_{p}$ isotherms has been a matter of interest due to the characteristic crossings observed for this property at high pressure and reflecting a change in the effective intermolecular potential with pressure [60]. As the density measurements by Schedemann et al. were made up to $397 \mathrm{~K}$ and $130 \mathrm{MPa}$, these data would be suited for the detailed study on the mechanical coefficients behavior in extended ranges of temperature and pressure.

The dependences of thermal expansivity on temperature along isobars, $\left(\alpha_{p}, T\right)_{p}$, and thermal expansivity on pressure along isotherms, $\left(\alpha_{p}, p\right)_{T}$, for the biodiesel studied by Schedemann et al. [27] are represented in Fig. 7. The observed behavior of $\alpha_{p}$, as a function of pressure was consistent with the expected one, i.e., it decreased with the increase in pressure at isothermal conditions (vd. Fig. 7b). The $\alpha_{p}$, isotherms show a clear intersection point nearly $65 \mathrm{MPa}$. This point obeys to the condition $\left(\partial \alpha_{p} / \partial T\right)_{p}=0$ meaning that $\alpha_{p}$ was independent of temperature at that pressure. This can be observed in Fig. 7a where $\alpha_{p}$ is represented as a function of temperature for isobaric conditions. At $64.8 \mathrm{MPa}$ the thermal expansivity was almost independent of temperature with value $(6.562 \pm 0.011) \times 10^{-4} \mathrm{~K}^{-1}$. In the figure it is shown that for pressures lower than $65 \mathrm{MPa}$ the thermal expansivity behaved normally, i.e., it increased as temperature rose at isobaric conditions particularly at low pressures. However, a small decrease of $\alpha_{p}$ with temperature was observed, for pressures higher than $65 \mathrm{MPa}$. The intersection of the $\alpha_{p}$ isotherms was observed for many liquids and was first described by Bridgman [61]. Some recent studies revealed
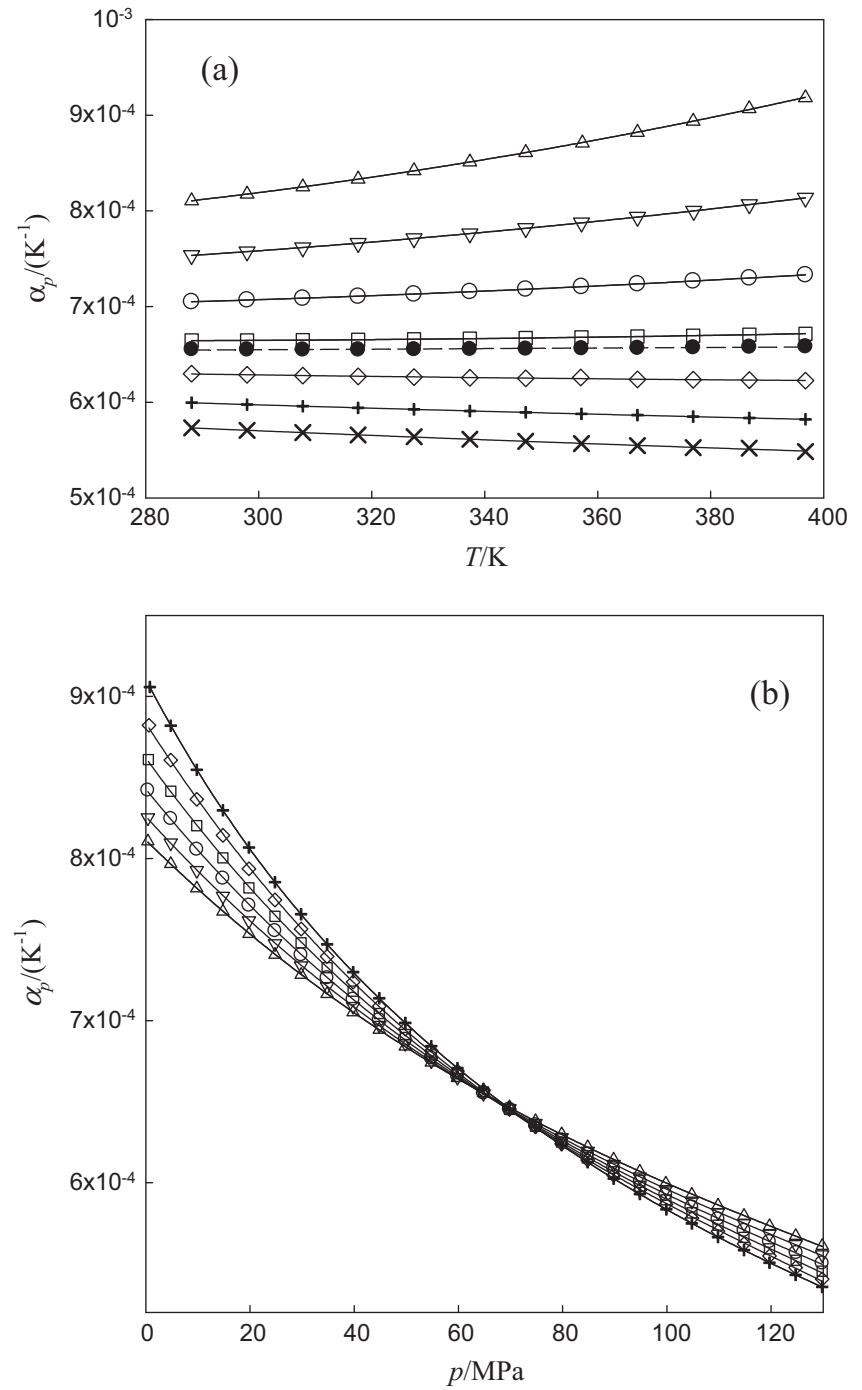

Fig. 7. Thermal expansivity $\left(\alpha_{p}\right)$ for the SCHB calculated from GMA EoS. (a) $\alpha_{p}$ as a function of temperature along isobars: $\Delta, 0.4-0.9 \mathrm{MPa} \nabla, 19.8 \mathrm{MPa} \bigcirc, 39.8 \mathrm{MPa}$ $\square, 59.8 \mathrm{MPa} ; \bullet, 64.8 \mathrm{MPa} ; \diamond, 79.8 \mathrm{MPa}$;, $99.8 \mathrm{MPa} \times, 119.7 \mathrm{MPa}$. (b) $\alpha_{p}$ as a function of pressure along isotherms: $\Delta, 288.12 \mathrm{~K} ; \nabla, 307.80 \mathrm{~K} ; \bigcirc, 327.49 \mathrm{~K} ; \square$, 347.26 K; $\diamond, 367.03 \mathrm{~K} ;+$, $386.84 \mathrm{~K}$.

that this behavior seems to be a general property of liquids and that such intersections are common to occur at pressures below $200 \mathrm{MPa}$ as indicated by the data collected by Taravillo et al. [62].

The calculation of $\alpha_{p}$, for our database fuels in the ranges 283.15-373.15 $\mathrm{K}$ and 0.1-40 MPa shows minimum and maximum values as presented in Fig. 8a. The averages for minimum and maximum values were, $(6.802 \pm 0.304) \times 10^{-4} \mathrm{~K}^{-1}$ and $(9.1$ $03 \pm 0.747) \times 10^{-4} \mathrm{~K}^{-1}$, respectively. For S and SR fuels the $\alpha_{p} \max -$ imum values showed markedly higher deviations from the average. The $\alpha_{p}$ values for the 19 biodiesels gave an average of $(8.237 \pm 0.249) \times 10^{-4} \mathrm{~K}^{-1}$ at $(T=298.15 \mathrm{~K}, p=0.1 \mathrm{MPa})$, which was practically the same value measured for the biodiesels set presented by Pratas et al. [36]. That value was near the one obtained for Diesel D-2 $\left(8.03 \times 10^{-4} \mathrm{~K}^{-1}\right)$, from the density data measured by Tat and Van Gerpen [21] at the same $(T, p)$ conditions. Santos et al. [63] presented almost the same thermal expansivity for diesel $\left(8.36 \times 10^{-4} \mathrm{~K}^{-1}\right)$ and corn biodiesel $\left(8.39 \times 10^{-4} \mathrm{~K}^{-1}\right)$ obtained from density measurements in the range of $283.15-323.15 \mathrm{~K}$ at atmospheric pressure. However, Aparício et al. [24] concluded that diesel had greater thermal expansivity than rapeseed biodiesel with differences increasing with temperature (7\% at $288.15 \mathrm{~K}$, $16 \%$ at $308.15 \mathrm{~K}$ and $22 \%$ at $328.15 \mathrm{~K}$ ). 

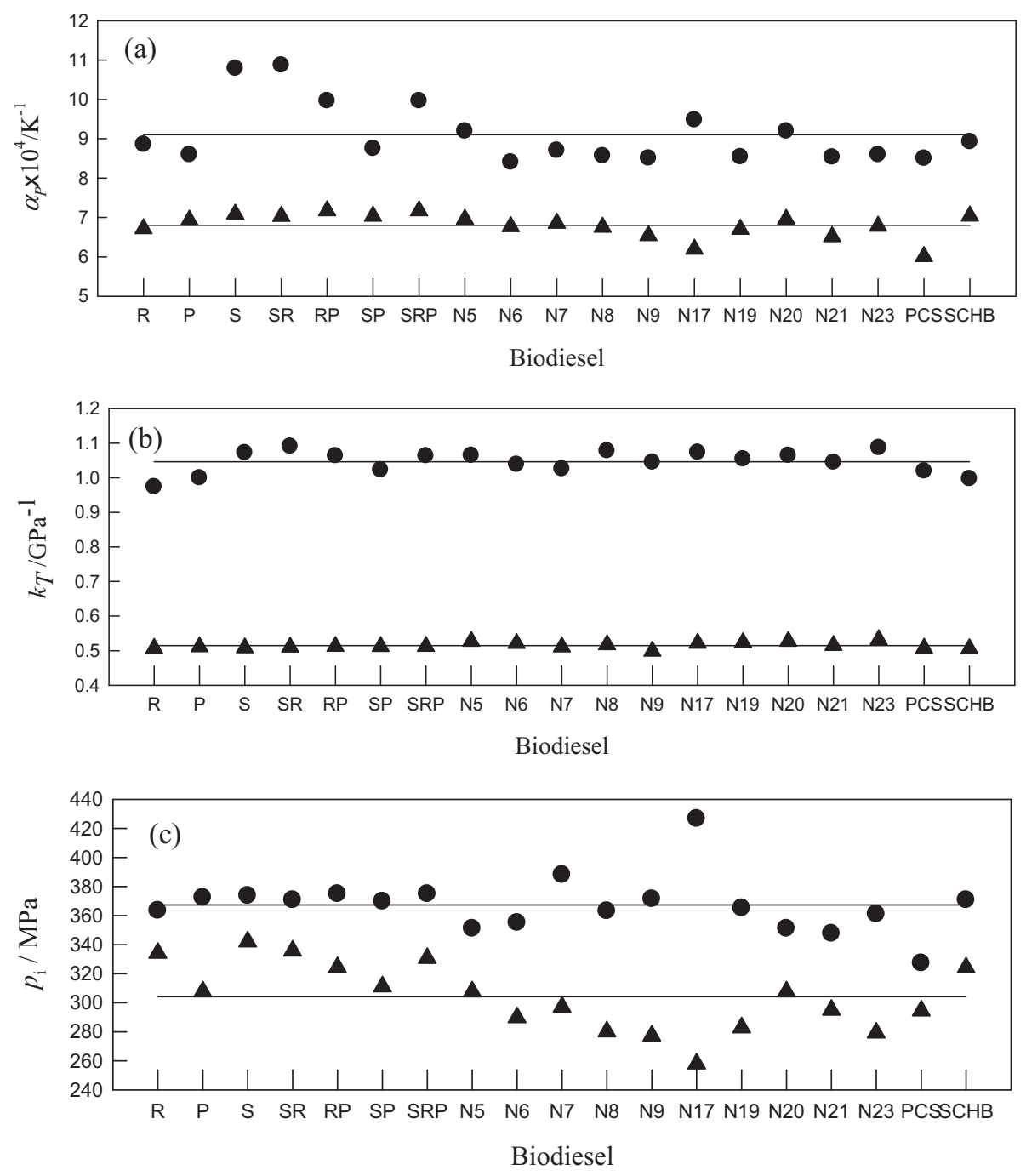

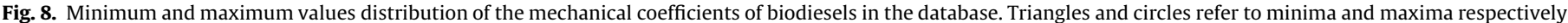
and lines to the mean values. (a) Thermal expansivity; (b) isothermal compressibility and (c) internal pressure.

Considering water and ethanol as standards at $298.15 \mathrm{~K}$ and $0.1 \mathrm{MPa}$, the thermal expansivity values of biodiesels were significantly higher than the one of water and lower than the corresponding value for ethanol (water: $2.57 \times 10^{-4} \mathrm{~K}^{-1}$ [64]; ethanol $\left.1.07 \times 10^{-3} \mathrm{~K}^{-1}[65]\right)$. The thermal expansivity is related to the engine power loss due to the fuel heating [1]. The higher the thermal expansivity the greater the power loss. From the results obtained for the several biodiesels in database and for diesel, significant differences in power due to corresponding differences in $\alpha_{p}$ were not expected. The thermal expansivity values for the biodiesel set (R, P, S, RP, RS, SP, SRP) obtained in this work with GMA EoS, were compared in Fig. S8a (supplementary material) with the ones from Tait EoS at pressures of $0.1 \mathrm{MPa}$ and $40 \mathrm{MPa}$ used for correlation by Pratas et al. [1]. The values calculated from the two EoS were in good agreement differing within $\pm 2 \%$ (less than $\left.2 \times 10^{-5} \mathrm{~K}^{-1}\right)$.

Concerning to $k_{T}$, the observed behavior for variations in temperature and pressure was according to the expected as illustrated in the $\left(k_{T}, T\right)_{p}$ and $\left(k_{T}, p\right)_{T}$ plots given in Fig. 9 for the biodiesel studied by Schedemann et al. [27]. Parabolic bends are observed for $k_{T}$ as the temperature increases, particularly at low pressure. A pronounced parabolic decrease of $k_{T}$ as pressure increased at fixed temperature was observed especially at the higher pressures. The minimum and maximum $k_{T}$ values for the 19 fuels in the ranges 283.15-373.15 $\mathrm{K}$ and $0.1-40 \mathrm{MPa}$, are shown in Fig. 8b. The average values for minimum and maximum of $k_{T}$ were $(0.515 \pm 0.0$ $08) \mathrm{GPa}^{-1}$ and $(1.046 \pm 0.032) \mathrm{GPa}^{-1}$, respectively. It was interesting to note the very small deviations from the average values. At 298.15 $\mathrm{K}$ and $0.1 \mathrm{MPa}$ the average $(0.68 \pm 0.01) \mathrm{GPa}^{-1}$ was obtained for the biodiesels in database. For Diesel D-2, the data from Tat and Van Gerpen gives $0.73 \mathrm{GPa}^{-1}$. Both these values were intermediate to the ones observed for water and ethanol (water: $0.452 \mathrm{GPa}^{-1}$ [64] ethanol: $1.40 \mathrm{GPa}^{-1}$ [65]). The isothermal compressibility values for the biodiesel set (R, P, S, RP, RS, SP, SRP) obtained with GMA EoS, were compared with the values from Tait EoS [1] (vd. Fig. S8b in supplementary material). At $0.1 \mathrm{MPa}$ the values from GMA were systematically $2 \%$ lower (ca $0.02 \mathrm{GPa}^{-1}$ ) than those reported by Pratas et al. while at $40 \mathrm{MPa}$ GMA produces values systematically higher with deviations usually less than $2 \%$.

Although rarely used in biodiesel research, the internal pressure $p_{i}$ provides a useful basis for understanding the nature of molecular interactions in liquid state. To our knowledge, only Schedemann et al. [27] presented values for this coefficient relative to methyl linoleate. The internal pressure is a macroscopic property used for estimating the cohesion of liquids, reflecting the molecular ordering, and it measures the change in the 

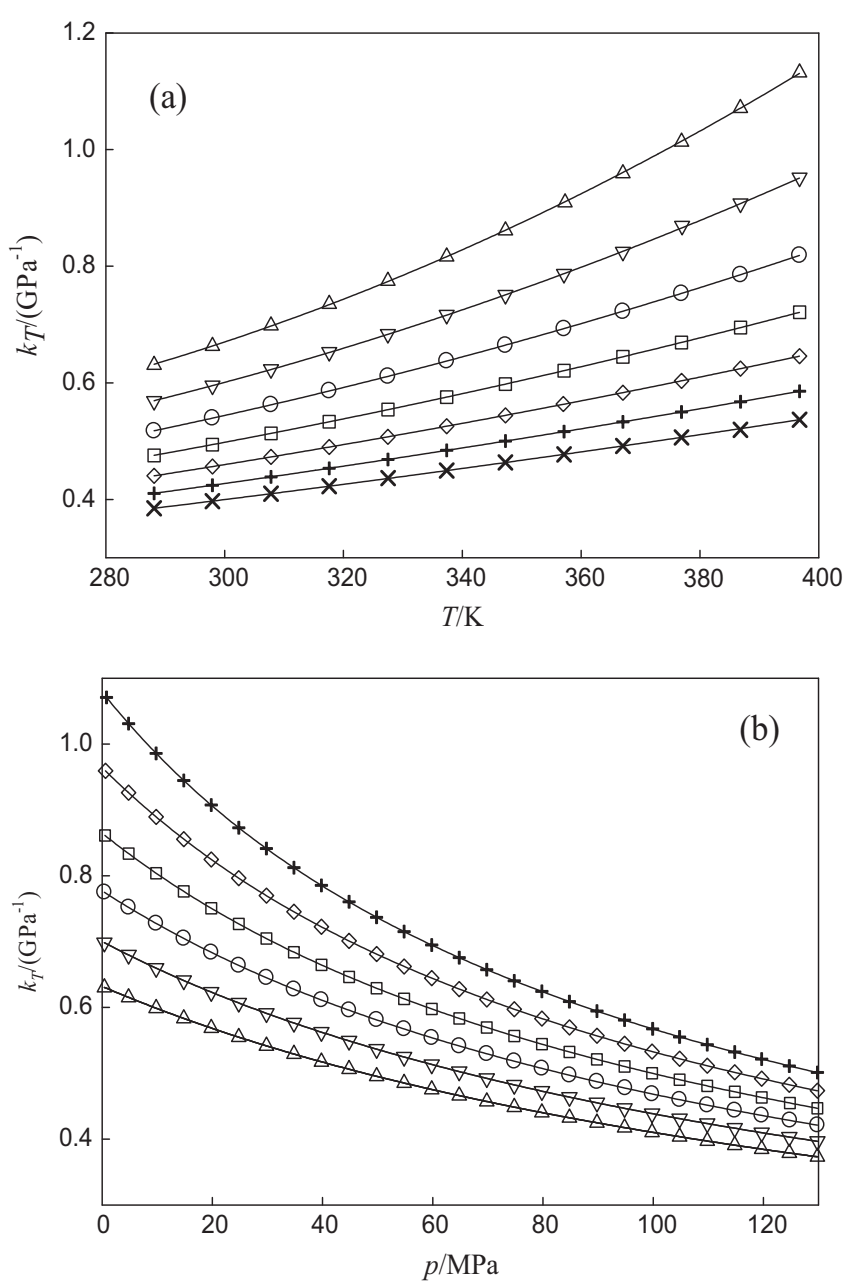

Fig. 9. Isothermal compressibility for the SCHB calculated from GMA EoS. (a) $k_{T}$ as a function of temperature along various isobars. Symbols as in Fig. 7a. (b) $k_{T}$ as a function of pressure along various isotherms. Symbols as in Fig. 7b.

internal energy as the liquid experiences a slight isothermal expansion. From the results obtained in this study for biodiesels, $p_{i}$ had low sensitivity to the pressure and temperature variations. For temperatures between $283.15 \mathrm{~K}$ and $373.15 \mathrm{~K}$ and pressures up to $40 \mathrm{MPa}$ the $p_{i}$ minimum and maximum averages for the 19 fuels were $(304 \pm 23) \mathrm{MPa}$ and $(367 \pm 19) \mathrm{MPa}$, respectively (see Fig. 8c). For pure liquids below their boiling points, $p_{i}$ is from 200 to $800 \mathrm{MPa}$, for non-associated and associated liquids, respectively [66]. The normal boiling temperatures for the considered biodiesels were in the range $T_{n b}=(611-650) \mathrm{K}[67,68]$. Therefore, biodiesel presents internal pressures near the lower limits for pure non-associated liquids. An isothermal decreasing with pressure is always observed, however for temperature the behavior was variable, depending on the fuel nature. The behavior of $p_{i}$ as a function of the temperature at $0.1 \mathrm{MPa}$ is shown in Fig. 10 for selected biodiesels. The most general behavior was a $p_{i}$ decreasing with temperature and for some fuels the decrease was more evident in the range of the studied temperatures, especially for the fuels prepared by Tat and Van Gerpen [2,21]. The cottonseed biodiesel produced in this work had the lowest internal pressure between all the studied 19 fuels. From the values of thermal expansion and isothermal compressibility given before at $298.15 \mathrm{~K}$ and atmospheric pressure the internal pressure of diesel D-2 is $327 \mathrm{MPa}$ in close agreement with what was found for biodiesel.

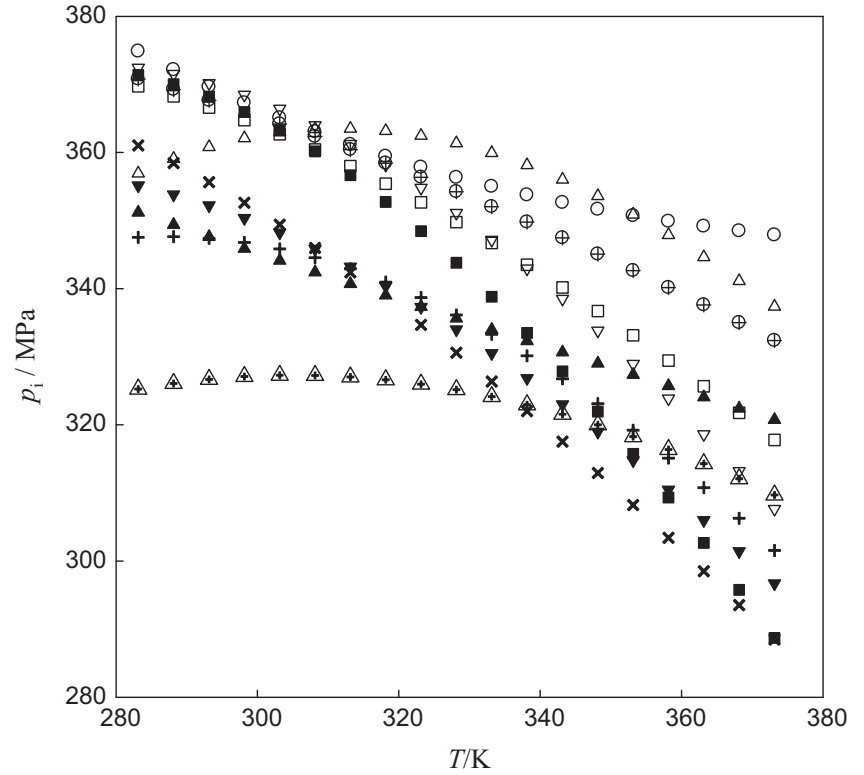

Fig. 10. Internal pressure $\left(p_{i}\right)$ as function of temperature at $0.1 \mathrm{MPa}$ for the biodiesels in the database. $\Delta, \mathrm{R} ; \nabla, \mathrm{P} ; \square, \mathrm{SP} ; \mathrm{O}, \mathrm{SRP} ; \mathbf{\Delta}, \mathrm{N} 5 ; \mathbf{\nabla}, \mathrm{N} 6 ; \mathbf{\square}, \mathrm{N} 9 ;+, \mathrm{N} 21 ; \times$, N23; 4 . PCS; $\oplus$, SCHB.

Given the molecular structure of the FAMEs composing the biodiesel, the attractive dispersion forces are the most important. They arise from induced dipoles and their strength are related with the polarizabilities of the molecules, which for different FAMEs in biodiesel are close no matter the alkyl chain length [69]. Although the presence of a carbonyl group provides some polarity to molecules, the two oxygen atoms of the ester functional group and the absence of an electropositive hydrogen within the FAME molecules prevent hydrogen bonding. The relative importance of the various molecular interactions (dispersion, polar, hydrogen bond) present in the liquid can be evaluated by comparing the internal pressure with the cohesive pressure. If the gas phase intermolecular interactions are excluded (perfect gas behavior assumed), the cohesive pressure (or cohesive energy density) $p_{\text {coh }}$ is given by [70]

$p_{\text {coh }}=\Delta_{l}^{g} U_{\text {coh }} / V_{m} \cong\left(\Delta_{l}^{g} H_{m}-R T\right) / V_{m}$

where $\Delta_{l}^{g} U_{\text {coh }}, \Delta_{l}^{g} H_{m}$, and $V_{m}$ are the molar cohesive energy, the molar enthalpy of vaporization, and molar volume (all usually taken at $0.1 \mathrm{MPa}$ ), respectively.

Following Ivanov and Abrosimov [70], the existence of strong intermolecular interactions in a liquid substantially increases the cohesive pressure relative to the internal pressure, while the internal pressure is comparable to the cohesive pressure for liquids without such strong intermolecular interactions. Taking water and ethanol as examples at $298.15 \mathrm{~K}$ and atmospheric pressure, and from the thermal expansion and isothermal compressibility values mentioned before, the internal pressures are $170 \mathrm{MPa}$ and $234 \mathrm{MPa}$, respectively. At the same $(T, p)$ conditions the cohesive pressures are increased to $2400 \mathrm{MPa}$ and $700 \mathrm{MPa}$ [71] for water and ethanol. These values reflect the strong hydrogen bonding, especially for water. For rapseed biodiesel, Yuan [72] reported the value $297 \mathrm{~J} \mathrm{~g}^{-1}$ for the enthalpy vaporization at $373.15 \mathrm{~K}$ and Lee and Hansen [73] the value $320 \mathrm{~J} \mathrm{~g}^{-1}$ for soybean biodiesel. From those values and density values by Pratas et al. [36], the corresponding cohesion pressures calculated with Eq. (20) are $236 \mathrm{MPa}$ and $274 \mathrm{MPa}$ for rapseed and soybean fuels. For rapeseed biodiesel Zhang et al. [74] and Cataldo et al. [75] refer $p_{\text {coh }}=308$ $\mathrm{MPa}$ and $p_{\mathrm{coh}}=277 \mathrm{MPa}$, respectively. Therefore, the internal pressure of biodiesel fuel is of the same magnitude order as the 
cohesion pressure, meaning that it behaves as non-associated liquid without strong molecular interactions.

\section{Conclusions}

New density experimental data for cottonseed biodiesel at temperatures between $288 \mathrm{~K}$ and $358 \mathrm{~K}$ and pressures up to $30 \mathrm{MPa}$ were measured with an estimated uncertainty of less than $\pm 1.6 \mathrm{~kg} \mathrm{~m}^{-3}$. To the best of our knowledge these are the first measurements for cottonseed biodiesel under high pressure.

The $p V T$ cottonseed biodiesel data were combined with similar information collected from literature regarding other 18 fuels, this way constituting a statistically significant database that was used to test the correlation performance of the GMA EoS. This equation was used for the first time to correlate the biodiesel density revealing excellent results, with standard deviations less than $0.5 \mathrm{~kg} \mathrm{~m}^{-3}$, corresponding to mean relative deviations less than $0.05 \%$. Regarding the extrapolation (or prediction) of GMA EoS at the $(p, T)$ conditions found in high efficient and high pressure injection systems, reliable extrapolated densities for high temperatures and pressures were obtained. Using the coefficients obtained from correlation in the restricted ranges of temperature (up to $357 \mathrm{~K}$ ) and pressure (up to $50 \mathrm{MPa}$ ) usually used in measurements, good density predictions (maximum deviations of $\approx 3 \mathrm{~kg} \mathrm{~m}^{-3}$ ) could be obtained at $400 \mathrm{~K}$ and $130 \mathrm{MPa}$.

Two new predictive equations of state for density, namely the DU and 4PGMA were developed and tested. Both EoS are simple to use and their application needs only the FAMEs profile of biodiesel. From the tests carried out in the 19 biodiesels from the database an overall average deviation of $0.42 \%$ corresponding to about $\approx 3 \mathrm{~kg} \mathrm{~m}^{-3}$ was found with DU method. For 4PGMA, the predicted maximum density deviation was $0.25 \%\left(\approx 2 \mathrm{~kg} \mathrm{~m}^{-3}\right)$. These results represent notable improvements in the prediction of biodiesel density in large temperature and pressure ranges where important operations in biodiesel processing take place. The isothermal compressibility increased with temperature at constant pressure, and decreased as pressure goes up for constant temperature as expected. The behavior of the thermal expansivity as a function of pressure was also the predictable, i.e., a decreasing is observed for increasing pressures at isothermal conditions. The $\alpha_{p}$ isotherms showed an evident intersection point nearly $65 \mathrm{MPa}$ and therefore, at this pressure $\alpha_{p}$ was independent from temperature. The internal pressure for all tested fuels was low and slightly higher than the cohesive pressure. This means that the biodiesel behaved as a non-associated liquid with weak molecular interactions.

\section{Acknowledgments}

This research is sponsored by FEDER funds through the program COMPETE - Programa Operacional Factores de Competitividade and by national funds through FCT - Fundação para a Ciência e a Tecnologia, under the project PEst-C/EME/UI0285/2013, and was also supported by a grant, EADIC II - ERASMUS MUNDUS ACTION 2 LOT 13A UE Mobility Programme 2010-2401/001-001 - EMA2. This work was done within the framework of the project EMSURE - W.P.4 of the program Energy and Mobility for Sustainable Regions. The authors acknowledge the support from Eng. Maria João Bastos during the Gas Chromatography tests of biodiesel fuels undertaken in the Chemical Process Engineering and Forest Products Research Centre.

\section{Appendix A. Supplementary material}

Supplementary data associated with this article can be found, in the online version, at http://dx.doi.org/10.1016/j.fuel.2014.09.113.

\section{References}

[1] Pratas MJ, Oliveira MB, Pastoriza-Gallego MJ, Queimada AJ, Pineiro MM, Coutinho JAP. High-pressure biodiesel density: experimental measurements, correlation, and cubic-plus-association equation of state (CPA EOS) modeling. Energy Fuels 2011;25:3806-14.

[2] Tat ME, Van Gerpen JH. Speed of sound and isentropic bulk modulus of alkyl monoesters at elevated temperatures and pressures. J Am Oil Chem Soc 2003;80:1249-56.

[3] Patil S, Akarte MM. Effect of injection pressure on CI engine performance fuelled with biodiesel and its blends. Int J Sci Eng Res 2012;3:1-4.

[4] Çelik MB, Simsek D. The determination of optimum injection pressure in an engine fuelled with soybean biodiesel/diesel blend. Therm Sci http:// dx.doi.org/10.2298/TSCl12807023C.

[5] Liu HP, Strank S, Werst M, Hebner R, Osara J. Combustion emissions modeling and testing of neat biodiesel fuels. In: Proceedings of the ASME 2010 4th international conference on energy sustainability ES2010, May 17-22, Phoenix (AZ, USA); 2010.

[6] Ghurri A, Kim JD, Kim HG, Jung JY, Song KK. The effect of injection pressure and fuel viscosity on the spray characteristics of biodiesel blends injected into an atmospheric chamber. J Mech Sci Technol 2012;26:2941-7.

[7] Seykens XLJ, Somers LMT, Baert RSG. Modeling of common rail fuel injection system and influence of fluid properties on injection process. In: Proceedings of VAFSEP 2004; 6-9 July 2004, Dublin, Ireland.

[8] Torres-Jimenez E, Svoljšak-Jerman M, Gregorc A, Lisec I, Dorado MP, Kegl B. Physical and chemical properties of ethanol-biodiesel blends for diesel engines. Energy Fuels 2010;24:2002-9.

[9] Enweremadu CC, Alamu OJ. Development and characterization of biodiesel from shea nut butter. Int Agrophys 2010;24:29-34.

[10] Alptekin E, Canakci M. Characterization of the key fuel properties of methyl ester-diesel fuel blends. Fuel 2009;88:75-80.

[11] Alptekin E, Canakci M. Determination of the density and the viscosities of biodiesel-diesel fuel blends. Renew Energy 2008;33:2623-30.

[12] Doll KM, Sharma BK, Suarez PAZ, Erhan SZ. Comparing biofuels obtained from pyrolysis, of soybean oil or soapstock, with traditional soybean biodiesel: density, kinematic viscosity, and surface tensions. Energy Fuels 2008;22:2061-6.

[13] Santos ICF, de Carvalho SHV, Solleti JI, Ferreira de La Salles W, Teixeira da Silva de La Salles K, Meneghetti SMP. Studies of Terminalia catappa L. oil: characterization and biodiesel production. Biores Technol 2008;99:6545-9.

[14] Tiwari AK, Kumar A, Raheman H. Biodiesel production from jatropha oil (Jatropha curcas) with high free fatty acids: an optimized process. Biomass Bioenergy 2007;31:569-75.

[15] Baroutian S, Aroua MK, Raman AAA, Sulaiman NMN. Viscosities and densities of binary and ternary blends of palm oil + palm biodiesel + diesel fuel at different temperatures. J Chem Eng Data 2010;55:504-7.

[16] Huber ML, Lemmon EW, Kazakov A, Ott LS, Bruno TJ. Model for the thermodynamic properties of a biodiesel fuel. Energy Fuels 2009:23:3790-7.

[17] Baroutian S, Aroua MK, Raman AAA, Sulaiman NMN. Density of palm oil-based methyl ester. J Chem Eng Data 2008;53:877-80.

[18] Baroutian S, Aroua MK, Raman AAA, Sulaiman NMN. Densities of ethyl esters produced from different vegetable oils. J Chem Eng Data 2008:53:2222-5.

[19] Tate RE, Watts KC, Allen CAW, Wilkie KI. The densities of three biodiesel fuels at temperatures up to $300{ }^{\circ} \mathrm{C}$. Fuel 2006;85:1004-9.

[20] Tat ME, Van Gerpen JH. The specific gravity of biodiesel and its blends with diesel fuel. J Am Oil Chem Soc 2000;77(2):115-9.

[21] Tat ME, Gerpen JH. Measurement of biodiesel speed of sound and its impact on injection timing. National Renewable Energy Laboratory 2003; NREL/SR-51031462.

[22] Tat ME, Gerpen JH, Soylu S, Canakci M, Monyem A, Wormley S. The speed of sound and isentropic bulk modulus of biodiesel at $21^{\circ} \mathrm{C}$ from atmospheric pressure to $35 \mathrm{MPa}$. J Am Oil Chem Soc 2000;77:285-9.

[23] Nikolić BD, Kegl B, Marcović SD, Mitrović MS. Determining the speed of sound, density and bulk modulus of rapeseed oil, biodiesel and diesel fuel. Therm Sci 2012;16(Suppl. 2):S569-79.

[24] Aparicio C, Guignon B, Rodriguez-Anton LM, Sanz PD. Determination of rapseed methyl ester oil volumetric properties in high pressure (0.1-350 MPa). J Therm Anal Calorim 2007;89:13-9.

[25] Dzida M, Prusakiewicz P. The effect of temperature and pressure on the physicochemical properties of petroleum diesel oil and biodiesel fuel. Fuel 2008;87:1941-8.

[26] Chhetri AB, Watts KC. Densities of canola, jatropha and soapnut biodiesel at elevated temperatures and pressures. Fuel 2012:99:210-6.

[27] Schedemann A, Wallek T, Zeymer M, Maly M, Gmehling J. Measurement and correlation of biodiesel densities at pressures up to $130 \mathrm{MPa}$. Fuel 2013;107:483-92.

[28] Dymond JH, Malhotra R. The Tait equation: 100 years on. Int J Thermophys 1988;9:941-51.

[29] Kontogeorgis GM, Michelsen ML, Folas GK, Derawi S, von Solms N, Stenby EH. Ten years with the CPA (Cubic-Plus-Association) equation of State Part I (pure compounds and self-associating system). Ind Eng Chem Res 2006;45:4855-68.

[30] Kontogeorgis GM, Michelsen ML, Folas GK, Derawi S, von Solms N, Stenby EH. Ten years with the CPA (Cubic-Plus-Association) equation of state part II (cross-associating and multicomponents system). Ind. Eng. Chem. Res. 2006;45:4869-78. 
[31] Schmid B, Gmehling J. From van der Waals to VTPR: the systematic improvement of the van der Waals equation of state. J Supercritical Fluids 2010;55:438-47.

[32] Weidlich U, Gmehling J. A modified UNIFAC model. 1. Prediction of VLE, hE, and gamma infinite. Ind Eng Chem Res 1987;26(7):1372-81.

[33] Gross J, Sadowski G. Application of perturbation theory to a hard-chain reference fluid: an equation of state for square-well chains. Fluid Phase Equilibria 2000;168:183-99.

[34] Oliveira MB, Freitas SVD, Llovell F, Vega LF, Coutinho JAP. Development of simple and transferable molecular models for biodiesel production with the soft-SAFT equation of state. Chem Eng Res Des; 2014. http://dx.doi.org/ 10.1016/j.cherd.2014.02.025.

[35] Dong NH, Thuy NT, Tho VDS. Predicting the temperature/pressure dependent density of biodiesel fuels. Petrovietnam J 2012;10:46-58.

[36] Pratas MJ, Freitas SVD, Oliveira MB, Monteiro SC, Lima AS, Coutinho JAP. Biodiesel density: experimental measurements and prediction models. Energy Fuels 2011;25:2333-40.

[37] Meng X, Jia M, Wang T. Predicting biodiesel densities over a wide temperature range up to 523 K. Fuel 2013;111:216-22.

[38] Spencer CF, Danner RP. Improved equation for prediction of saturated liquid density. J Chem Eng Data 1972;17:236-41.

[39] Goharshadi EK, Morsali A, Abbaspour M. New regularities and an equation of state for liquids. Fluid Phase Equilib 2005;230:170-5.

[40] Nogueira CA, Feitosa FX, Fernandes FAN, Santiago RS, Sant'Ana HB. Densities and viscosities of binary mixtures of babassu biodiesel + cotton seed or soybean biodiesel at different temperatures. J Chem Eng Data 2010;55:5305-10.

[41] Altin R, Çetinkaya S, Yücesu HS. The potential of using vegetable oil fuels as fuel for diesel engines. Energy Convers Manage 2001;42(5):529-38.

[42] Lopes DC, Neto AJS. Potential crops for biodiesel production in Brazil: a review. World J Agric Sci 2011;7(2):206-17.

[43] Rashid U, Anwar F, Knothe G. Evaluation of biodiesel obtained from cottonseed oil. Fuel Process Technol 2009;90(9):1157-63.

[44] Sarada SN, Shailaja M, Raju AVSR, Radha KK. Optimization of injection pressure for a compression ignition engine with cotton seed oil as an alternate fuel. Int J Eng Sci Technol 2010;2(6):142-9.

[45] Carlos EF, Talavera-Prieto MC, Fonseca IMA, Portugal ATG, Ferreira AGM. Measurements of $p V T$, viscosity, and surface tension of trihexyltetradecylphosphonium tris(pentafluoroethyl)trifluorophosphate ionic liquid and modelling with equations of state. J Chem Thermodyn 2012;47:183-96.

[46] Fluid properties for water; June 2014 <http://webbook.nist.gov/chemistry/ fluid/>.

[47] Private communication from Anton Parr; 2005.

[48] Sun TF, Ten Seldam CA, Kortbeek PJ, Trappeniers NJ, Biswas SN. Acoustic and thermodynamic properties of ethanol from 273.15 to $333.15 \mathrm{~K}$ and up to 280 MPa. Phys Chem Liq 1988;18:107-16.

[49] Ramos MJ, Fernández CM, Casas A, Rodríguez L, Pérez A. Influence of fatty acid composition of raw materials on biodiesel properties. Bioresour Technol 2008; 100:261-8.

[50] Mohibbe A, Amtul W, Nahar NM. Prospect and potential of fatty acid methyl esters of some non-traditional seeds oils for use as biodiesel in India. Biomass Bioenergy 2005;29:293-302.

[51] Islam MA, Magnusson M, Brown RJ, Ayoko GA, Nabi N, Heimann K. Microalgal species selection for biodiesel production based on fuel properties derived from fatty acid profiles. Energies 2013;6(11):5676-702.

[52] EN 14214. Fatty acid methyl esters (FAME) for diesel engines. Requirements and test methods. European Committee for Standardization: Management Centre, rue de Stassart 36, B-1050, Brussels; 2003.

[53] Elbro HS, Fredenslund A, Rasmussen P. Group contribution method for the prediction of liquid densities as a function of temperature for solvents, oligomers, and polymers. Ind Eng Chem Res 1991;30:2576-82.
[54] Ihmels EC, Gmehling J. Extension and revision of the group contribution method GCVOL for the prediction of pure compound liquid densities. Ind Eng Chem Res 2003;42:408-12.

[55] Pratas MJ, Freitas S, Oliveira MB, Monteiro SC, Lima AS, Coutinho JAP. Densities and viscosities of fatty acid methyl and ethyl esters. J Chem Eng Data 2010;55:3983-90.

[56] Pratas MJ, Freitas S, Oliveira MB, Monteiro SC, Lima AS, Coutinho JAP. Densities and viscosities of minority fatty acid methyl and ethyl esters present in biodiesel. J Chem Eng Data 2011;56:2175-80.

[57] Ndiaye HI, Habrioux M, Coutinho JAP, Paredes MLL, Daridon JL. Speed of sound density, and derivative properties of ethyl myristate, methyl myristate, and methyl palmitate under high pressure. J Chem Eng Data 2013;58:1371-7.

[58] Outcalt SL. Compressed-liquid density measurements of methyl oleate and methyl linoleate. J Chem Eng Data 2011;56:4239-43.

[59] Goharshadi EK, Moosavi M. Thermodynamic properties of some ionic liquids using a simple equation of state. J Mol Liq 2008;142:41-4.

[60] Randzio SL. An attempt to explain thermal properties of liquids at high pressures. Phys Lett 1986;A117:473-6.

[61] Bridgman PW. The physics of high pressure. New York: Dover Publications; 1970.

[62] Taravillo M, Baonza VG, Caceres M, Nunez J. Thermodynamic regularities in compressed liquids: I. The thermal expansion coefficient. J Phys Condens Mater 2003:15:2979-89.

[63] Santos DQ, Lima AL, Lima AP, Neto WB, Fabris JD. Thermal expansion coefficient and algebraic models to correct values of specific mass as a function of temperature for corn biodiesel. Fuel 2013;106:646-50.

[64] Chen TC, Fine RA, Millero FJ. The equation of state of pure water determined from sound speeds. J Chem Phys 1977;66:2142-4

[65] Gonçalves FAMM, Trindade AR, Costa CSMF, Bernardo JS, Johnson I, Fonseca IMA, et al. PVT, viscosity, and surface tension of ethanol: new measurements and literature data evaluation. J Chem Thermodyn 2010;42:1039-49.

[66] Zorębski E. Internal pressure studies of alcohols on the basis of ultrasonic measurements. Mol Quantum Acoust 2005;26:317-26.

[67] Goodrum JW. Volatility and boiling points of biodiesel from vegetable oils and tallow. Biomass Bioenergy 2002;22:205-11.

[68] Yuan W, Hansen AC, Zhang Q. Vapor pressure and normal boiling point predictions for pure methyl esters and biodiesel fuels. Fuel 2005;84:943-50.

[69] Gonzalez YM, De Caro P, Thiebaud-Roux S, Lacaze-Dufaure C. Fatty acid methyl esters as biosolvents of epoxy resins: a physicochemical study. J Solution Chem 2007;36(4):437-46.

[70] Ivanov EV, Abrosimov VK. Relationship between the internal pressure and the cohesive energy density of a liquid nonelectrolyte. Consequences of application of Dacks concept. J Struct Chem 2005;46(5):856-61.

[71] Cabane B, Vuilleumier R. The physics of liquid water. CR Geosci 2005;337(1 2):159-71.

[72] Yuan W. Computational modeling of NOx emissions from biodiese combustion based on accurate fuel properties. PhD dissertation. Urbana (IL): University of Illinois at Urbana-Champaign, Department of Agricultural and Biological Engineering; 2005.

[73] Lee CF, Hansen AC. Investigation of bio-diesel fueled engines under lowtemperature combustion strategies. FINAL REPORT DE-FC26-05NT42634. Board of Trustees of the University of Illinois, submitted to U.S. Department of Energy, National Energy Technology Laboratory.

[74] Zhang Y, Mallapragada SK, Narasimhan B. Dissolution of waste plastics in biodiesel. Polym Eng Sci 2010;50: 863-70.

[75] Cataldo F, Ursini O, Angelini G. Biodiesel as a plasticizer of a SBR-based tire tread formulation; 2013. Article ID 340426, 9 pages http://dx.doi.org/10.1155/ $2013 / 340426$. 